Cómo citar este trabajo: Ojeda-Rivera, J. F., Andreu-Lara, C., \& Infante-Amate, J. (2018). Razones y recelos de un reconocimiento patrimonial: los paisajes del olivar andaluz. Boletín de la Asociación de Geógrafos Españoles, 79, 2471, 1-29. http://dx.doi.org/10.21138/bage.2471

\title{
Razones y recelos de un reconocimiento patrimonial: los paisajes del olivar andaluz
}

\author{
Reasons and misgivings of a heritage recognition: \\ the olive grove landscapes of Andalusia \\ Juan Francisco Ojeda-Rivera \\ jfojeriv@upo.es \\ Departamento de Geografía, Historia y Filosofía \\ Universidad Pablo Olavide (España)
}

Carmen Andreu-Lara

carmenandreu@us.es

Departamento de Pintura

Universidad de Sevilla (España)

Juan Infante-Amate

jinfama@upo.es

Departamento de Geografía, Historia y Filosofía

Universidad Pablo Olavide (España)

\begin{abstract}
Resumen
El 27 de enero de 2017, la UNESCO ha incluido al paisaje del olivar andaluz en una lista tentativa de futuros patrimonios mundiales, lo que presenta oficialmente en el mundo estos paisajes y exige mantener sus valores patrimoniales. Aquí se ofrece una lectura científica e interdisciplinar de las claves geográficas, históricas y estéticas que justifican tal consideración y también se presenta la problemática ambiental y social que está suponiendo para aquellos seculares paisajes la adopción de insumos y manejos insostenibles del olivo para adaptar sus producciones a un exigente mercado.
\end{abstract}


Palabras clave: Geografía; historia; pintura; ecología; paisaje; olivar.

\begin{abstract}
Last 27th of January 2017, UNESCO included The Olive Grove Landscapes of Andalusia in a preliminary list of candidates to become part of World Heritage list, which would mean a global recognition of this landscape and its a call for maintaining their heritage values. The goal of this paper is to analyze, through a scientific and transdisciplinary approach, the arguments for and against such recognition. We thus explore the geographic, historic, cultural, and aesthetic reasons that would justify the inclusion of this landscape in the World Heritage list. Moreover, we aim to assess and discus the environmental and social challenges faced by olive agro-ecosystems as a result of recent industrial management and global demands.
\end{abstract}

Key words: Geography; history; painting; ecology; landscape; olive.

\title{
1 Introducción
}

El olivar es el cultivo mediterráneo por excelencia. Sus requerimientos vegetativos se adaptan a las especiales condiciones agroclimáticas de la mediterraneidad, de manera que, además de extenderse por las tierras que bordean al Mare Nostrum, también está presente en las otras regiones mediterráneas del planeta (California, Chile, Suráfrica o Australia). Pero no sólo estamos ante un vegetal de una singular adaptación espacial, sino sobre todo ante una cultura y un cultivo de larga y fecunda tradición histórica, que hunde sus raíces en los primeros procesos de domesticación agraria y que ha tenido un papel central en la ecología, la economía, la historia y la belleza del Mediterráneo y sus paisajes. Y dentro de tal ambiente, ocupa un lugar primero en Andalucía, donde destaca por extensión y por una importancia milenaria como fuente de riqueza y sustento de las primeras civilizaciones asentadas en la península ibérica.

El olivar, en consecuencia, representa un paisaje de valor universal y excepcional por su geografía, su historia, su etnología y su estética. Tales perspectivas son nuestras referencias para reivindicar este cultivo como patrimonio de la humanidad, intentando - con este texto- ordenar elementos y argumentos que - desde un diálogo interdisciplinar - evidencien tal valoración patrimonial, evitando tópicos escasamente fundamentados sobre su origen, su función, su expansión, su morfología, sus paisajes o su importancia.

Nuestro texto presentará el proceso histórico de expansión del olivar en Andalucía y reconstruirá su distribución geográfica desde 1750. Ello nos permitirá conocer sus principales áreas de expansión en estas latitudes durante los últimos dos siglos y medio e ir descubriendo las claves geohistóricas del olivar andaluz y sus diferentes morfologías, relacionándolas con sus cambiantes manejos y sistemas de explotación, cuyos hitos vendrán marcados por transformaciones tecnológicas o por los 
distintos papeles económicos, sociales y culturales que se le han ido otorgando a lo largo de la historia y en las distintas comarcas de la región.

Todo ello culminará en una lectura directa, hermenéutica y transdisciplinar de paisajes del olivar existentes hoy en Andalucía, mostrando no sólo las formas objetivas presentes en distintas áreas del territorio, sino también sus percepciones y las emociones que suscitan.

En definitiva, nuestro objetivo es apuntalar - desde una mirada compartida e interdisciplinar - las bases espaciales, territoriales y paisajísticas del olivar andaluz, poniendo en evidencia sus caracteres excepcionales de adaptación ecológica, su papel histórico fundamental en la economía y la sociedad regional y su importancia secular como paisaje fundante de Andalucía, que merecerá ser incluido en la definitiva lista de Patrimonio Mundial de la UNESCO. ${ }^{1}$ Pero el conocimiento riguroso de tales valoraciones nos exige adoptar también una cierta cautela ante tal honor: En las tres últimas décadas del siglo XX, principalmente, el olivar ha mostrado un proceso de transición productiva hacia manejos industriales para quedar inserto en dinámicas mercantiles a escala global que ponen en cuestión algunos de los valores singulares de este cultivo milenario e incluso su propia sostenibilidad. ${ }^{2}$ Aun teniendo en cuenta que el paisaje es una realidad dinámica que no debe fosilizarse, entendemos que muchos de los olivares que hoy pueblan nuestros campos responden a un modelo que ha roto demasiados hilos con aquel olivar cuyos valores y dinamismo iremos descubriendo como economía y símbolo del Mediterráneo. Son muy serios los problemas ambientales (erosión, contaminación de suelo y agua, pérdida de biodiversidad...) y socioeconómicos (temporalidad del trabajo, migración estacional, pérdida de rentabilidad...) que hoy está produciendo el olivar en Andalucía y que serán presentados al final de este texto, donde mostraremos una mirada crítica a la propia sublimación de los paisajes de olivar que, paradójicamente, pretendemos apoyar.

\section{Claves geohistóricas del olivar}

El cultivo del olivo ha estado presente en todas las civilizaciones mediterráneas. Su aparición dała 5 milenios fruto de la domesticación de su variedad silvestre, el acebuche, y desde entonces ha jugado un papel fundamental en su economía y su cultura (Loumou \& Giourga, 2003) Aunque sabemos de su formidable importancia ya en el mundo antiguo, no ha sido hasta tiempos contemporáneos cuando su ocupación ha alcanzado los niveles masivos que hoy caracterizan muchas zonas olivareras del Mediterráneo. Solo hasta hace poco más de 100 años es posible documentar cuantitativamente su importancia global. En la primera década del siglo XX, solo tres

1 Propuesta oficializada el 27 de enero de 2017 según se recoge en la web de la UNESCO. Más detalles en http://whc.unesco.org/en/tentativelists/6169/

2 Aunque es cierto que algunos problemas se evidenciaros ya a finales del siglo XIX y a mediados del XX (e.g. Vanwalleghem et al., 2011; Infante-Amate, 2014; Lima Cueto et al., 2017). 
países (España, Italia y Grecia) concentraban más del 80\% de la producción de aceite de oliva. En la actualidad, ese porcentaje ha bajado sensiblemente por el crecimiento productivo en otras zonas del norte de África así como en "otros mediterráneos climáticos" como California, Chile-Argentina o Australia (Figura 1a).

Figura 1. El olivar español en el sistema olivarero mundial

Figura 1a. Producciones mundiales de aceite de oliva (media 2011/15)

a) Mapa de la producción mundial de aceite de oliva

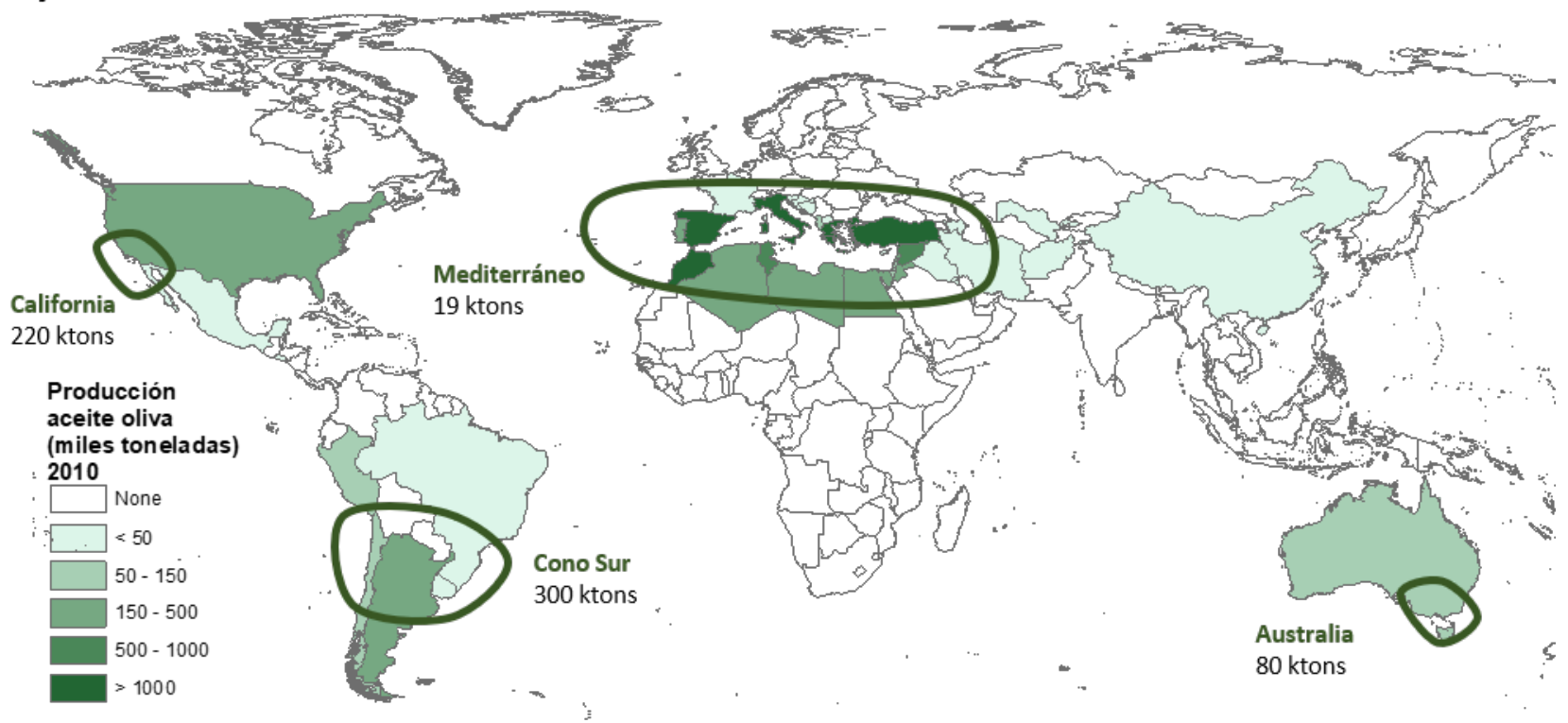

Figura 1b. Distribución del olivar en España por municipios en 2009

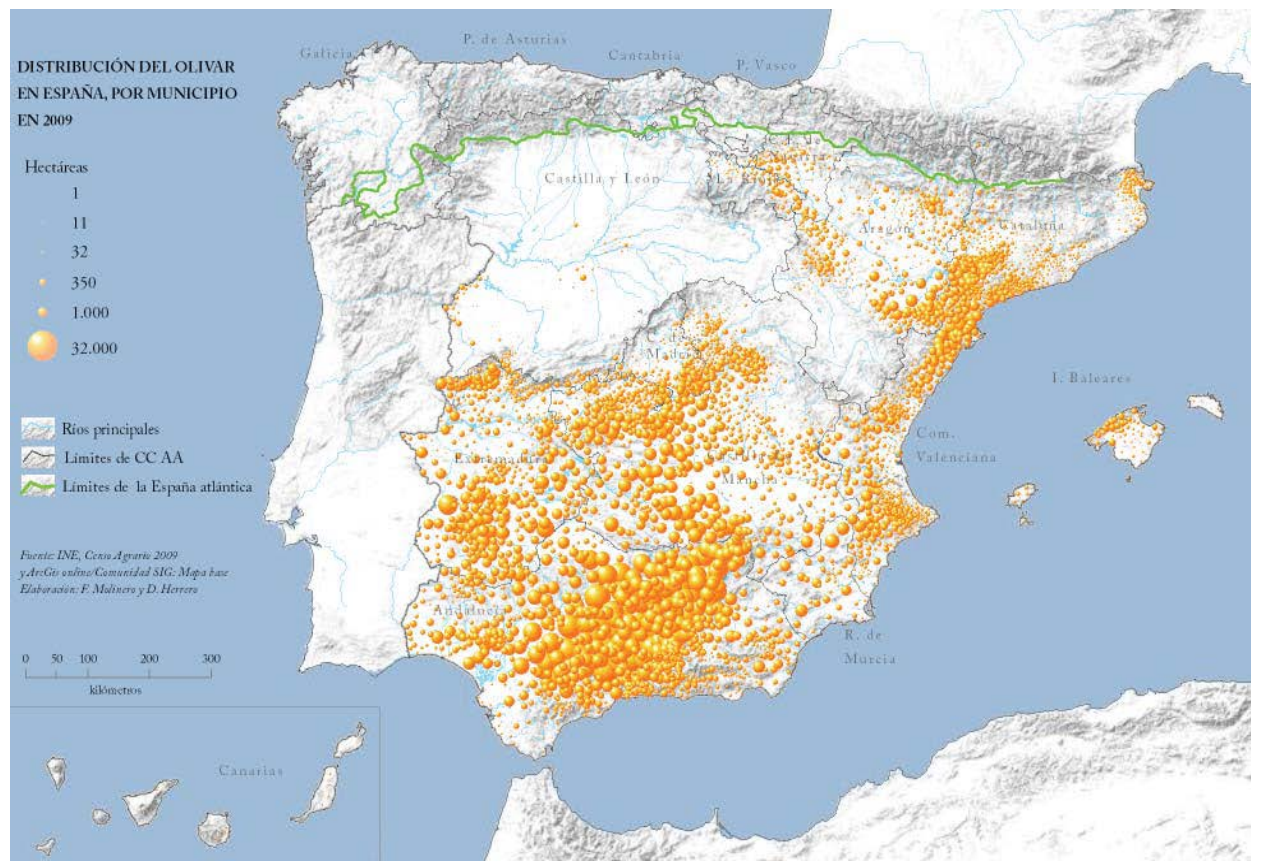

Fuente: 1a) FAOSTAT (2018); y 1b) INE (2009) y Molinero et al. (2013) 
Entre los principales países productores sabemos que Italia fue el mayor suministrador a nivel mundial -conectado con las demandas de la Revolución Industrial inglesa- hasta finales del XIX, cuando debido a la crisis agraria finisecular España se convirtió en principal productor. Si bien es cierto que la crisis también afectó a España, su sector oleícola se reestructuró iniciando una senda de crecimiento que se aceleró en las tres primeras décadas del siglo XX. La crisis italiana perduró. En España, tras el apagón del sector en los años de la Guerra y el primer franquismo, la superficie y la producción siguieron creciendo hasta copar una cuarta parte de la superficie de olivar global y hasta un 40 \% de la producción (Zambrana, 1987).

\section{Tabla 1. Evolución de las superficies de olivar en regiones españolas}

\begin{tabular}{|l|c|c|c|c|c|c|c|c|}
\cline { 2 - 9 } \multicolumn{1}{c|}{} & \multicolumn{4}{c|}{ Miles de hectáreas } & \multicolumn{2}{c|}{ \% del país } & $\begin{array}{c}\text { \% del } \\
\text { mundo }\end{array}$ \\
\cline { 2 - 10 } \multicolumn{1}{c|}{} & 1858 & 1888 & 1930 & 1960 & 2015 & 1858 & 2015 & 2015 \\
\hline Andalucía & 411 & 643 & 952 & 1.212 & 1.561 & 47,9 & 61,8 & 15,2 \\
Castilla-LM & 114 & 108 & 249 & 330 & 371 & 13,3 & 14,7 & 3,6 \\
Extremadura & 40 & 60 & 151 & 229 & 265 & 4,7 & 10,5 & 2,6 \\
\hline Zona Sur & 565 & 811 & 1353 & 1771 & 2197 & 65,9 & 87,0 & 21,4 \\
\hline Cataluña & 112 & 140 & 191 & 213 & 116 & 13,1 & 4,6 & 1,1 \\
Valencia & 69 & 75 & 140 & 132 & 91 & 8,0 & 3,6 & 0,9 \\
Baleares & 33 & 27 & 22 & 17 & 8 & 3,9 & 0,3 & 0,1 \\
Murcia & 3 & 26 & 36 & 30 & 19 & 0,3 & 0,8 & 0,2 \\
\hline Zona Levante & 217 & 268 & 389 & 392 & 234 & 25,3 & 9,3 & 2,3 \\
\hline Resto de España & 76 & 135 & 281 & 286 & 95 & 8,8 & 3,8 & 0,9 \\
\hline España & 858 & 1139 & 1882 & 2316 & 2526 & 100,0 & 100,0 & 24,6 \\
\hline
\end{tabular}

Fuente: para 1858, Zambrana (1987); para 1888, Junta Consultiva Agronómica (1891);

y para el resto de años se han tomado los anuarios del Ministerio de Agricultura.

El porcentaje del mundo se ha estimado en base a FAOSTAT (2018)

El crecimiento del olivar en España se ha explicado por varios factores en distintas fases históricas. A lo largo del siglo XIX creció como cultivo campesino capaz se suministrar una amplia gama de productos como la leña, las hojas, el orujo, etc. que sustituían los productos de los deforestados montes. A finales del XIX, más competitivo que el italiano, fue ocupando los crecientes mercados internacionales igual que ocurrió tras la reapertura económica española después de varias décadas de políticas autárquicas que ahogaron la expansión exterior del sector (Infante-Amate, 2014).

A nivel geográfico el olivar español se ha ido concentrando en el sur, principalmente en Andalucía (Figura 1b). Aunque su presencia fue generalizada en la zona mediterránea del país (sur y levante), desde el siglo XIX las provincias levantinas fueron perdiendo superficie de olivar para concentrarse en la parte meridional donde hoy se encuentra el gran mar de olivos español. Así (Tabla 1) Baleares, pierde olivares ya desde el siglo XIX, Valencia, desde 1930 y Cataluña, especialmente, en la segunda mitad del siglo XX. En 1858, la zona mediterránea levantina concentraba más de un 
$25 \%$ de la superficie de olivar del país y hoy no alcanza el $10 \%$. En definitiva, el aumento del olivar español se explica por el gran avance del cultivo en Andalucía que, en el último siglo y medio ha sumado el 70 \% de las nuevas plantaciones en una tendencia de crecimiento continuado, lo que, de entrada, retrata un primer cambio en los paisajes agrarios de la región: presencia cada vez más dominante del olivar. Si a mediados del siglo XVIII la superficie era de unas 225 mil hectáreas, en 1888 había superado las 643 mil y en la actualidad alcanza el millón y medio.

La Figura 2 representa las proporciones de superficie olivarera en Andalucía -a escala municipalrespecto de la superficie total de cada municipio en cuatro hitos históricos escogidos (1750, 1880, 1960 y 2010) y representativos porque marcan otras tantas etapas significativas en la expansión del olivar andaluz.

Figura 2. Ámbitos de la región andaluza y evolución de la expansión del olivar en sus municipios
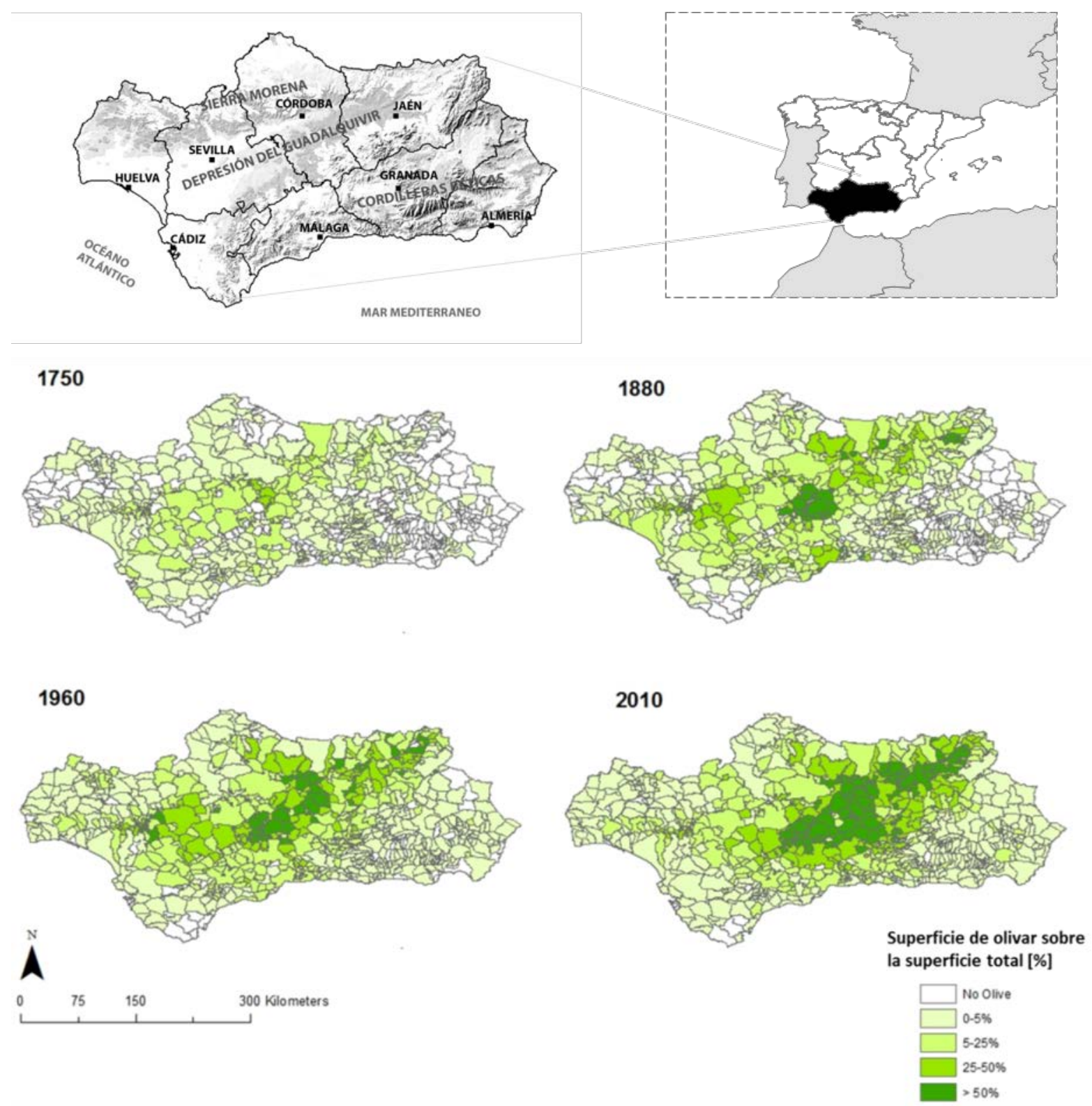

Fuente: Infante-Amate et al. (2016) 
En 1750 el olivar se abría paso en una sociedad preindustrial y con un marco institucional preliberal que condicionaba su expansión. La superficie de olivar era todavía muy limitada y se concentraba principalmente en la campiña sur de las provincias de Sevilla y Córdoba, lo que parece explicarse porque en aquellos territorios centrales de la región se cruzaban los principales corredores comerciales que conectaban los puertos marítimos con los pasos hacia interior del país.

Hasta mediados del siglo XIX, el olivar mantuvo una senda expansiva relativamente análoga en las provincias del interior de la región: Sevilla, Córdoba y Jaén concentraban en 1858 casi el $90 \%$ del olivar andaluz. En 1880, el segundo mapa de la Figura 3 revela que el corredor olivarero existente en 1750 mantenía la misma trayectoria con la única variación de que la concentración de olivos en la Campiña cordobesa (núcleo central de la región) se había hecho mucho más prominente, hasta convertirla en el epicentro oleícola andaluz.

En las primeras décadas del siglo XX, Córdoba y Jaén (centro y noreste) aceleraron su crecimiento de manera notable. Hacia 1960 era raro encontrar un municipio en la provincia de Jaén (que alberga desde entonces la mayor concentración olivarera) con menos de una tercera parte de su superficie cubierta por olivos. Este proceso se aceleró en las últimas décadas del siglo XX. En los municipios olivareros del corazón de Andalucía el cultivo creció hasta levantar la mayor concentración arbórea cultivada de Europa y probablemente del mundo. En los últimos años asistimos al que parece ser un nuevo proceso de expansión del olivar en zonas de campiña caracterizado por manejos hiperintensivos.

En resumen, aunque de importancia milenaria -las evidencias del comercio con la Bética son inexcusables - la masiva presencia del olivar constituye un fenómeno relativamente contemporáneo, ya que su gran expansión en España data del siglo XIX, porque en los contextos preindustriales, la recurrente limitación de establecer fluidas redes de transporte y de disociar las actividades de producción y consumo limitó ampliamente el desarrollo de monocultivos (Sieferle, 2001). Desde inicios del siglo XX, el cultivo estuvo presente en todo el país, aunque fue declinando del Levante peninsular y creciendo en el sur, hasta convertirse hoy en el proverbial "mar de olivos", ocupante de las antiguas olas del mar Mioceno en las campiñas altas de Andalucía (Figura 3). 


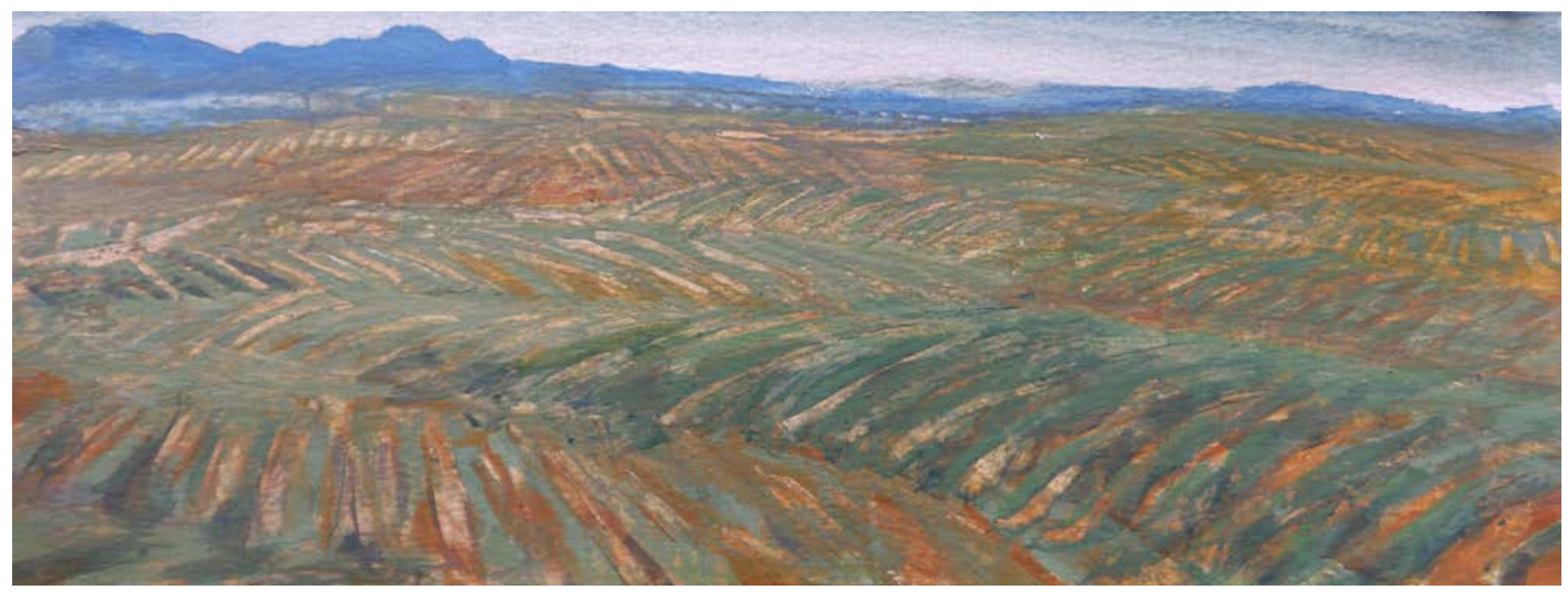

Fuente: Carmen Andreu, Mar de Olivos.

Temple de huevo sobre papel, 15 x $40 \mathrm{~cm}$. (2011)

\section{Dinámica de manejos y sistemas de explotación del olivar andaluz}

En la perspectiva de largo plazo, con la que aquí se trabaja, es posible establecer también una trayectoria de los grandes cambios que en Andalucía -y al socaire de las transformaciones técnicas y funcionales y de los distintos discursos sobre el olivar - se han ido produciendo en los sucesivos manejos de este árbol cultivado, conducentes a distintos sistemas de explotación del mismo.

\subsection{Olivares primitivos: desde dispersos entre matorrales y cultivos hasta adehesados}

A mediados del siglo XVIII, Andalucía tenía una de las densidades de población más bajas de España $\left(20 \mathrm{hab} / \mathrm{km}^{2}\right.$ ), lo que, unido a las restricciones institucionales que frenaban el proceso de colonización agrícola, explicaba que más de la mitad del territorio estuviera todavía dedicado a pasto y monte. Además, la mayor parte de la superficie era ocupada por cereales y labrada con rotaciones muy extensivas.

El olivar del Antiguo Régimen, poco capitalizado y con un marcado carácter multifuncional aparecía como un aprovechamiento más próximo a manejos agroforestales, como la dehesa o el montado, que al actual cultivo intensivo y ordenado en hileras. En otros trabajos - que estudian los contratos de arrendamiento de olivar en la región, entre 1740 y 1850- se ha documentado la morfología de los sistemas olivareros de explotación. Así, en los olivares de sierras y comarcas no campiñesas, que -como se ha visto en la Figura 2- eran los territorios menos propicios a la extensión del cultivo, los olivos aparecían dispersos a lo largo del territorio sin formar filas ordenadas y, en algunos casos, asociados a otros cultivos. De hecho, las fuentes catastrales de 1750 señalan más de un centenar de municipios en los que se apunta que hay olivos en el término, pero en los que no se catastra ninguna finca de olivar. Árboles dispersos, salpicando los paisajes de sierras y 
comarcas marginales, integrados en los ruedos y territorios agrícolas cercanos a las poblaciones o combinados con aprovechamientos ganaderos (Figura 4).

\section{Figura 4. Olivar disperso de montaña}

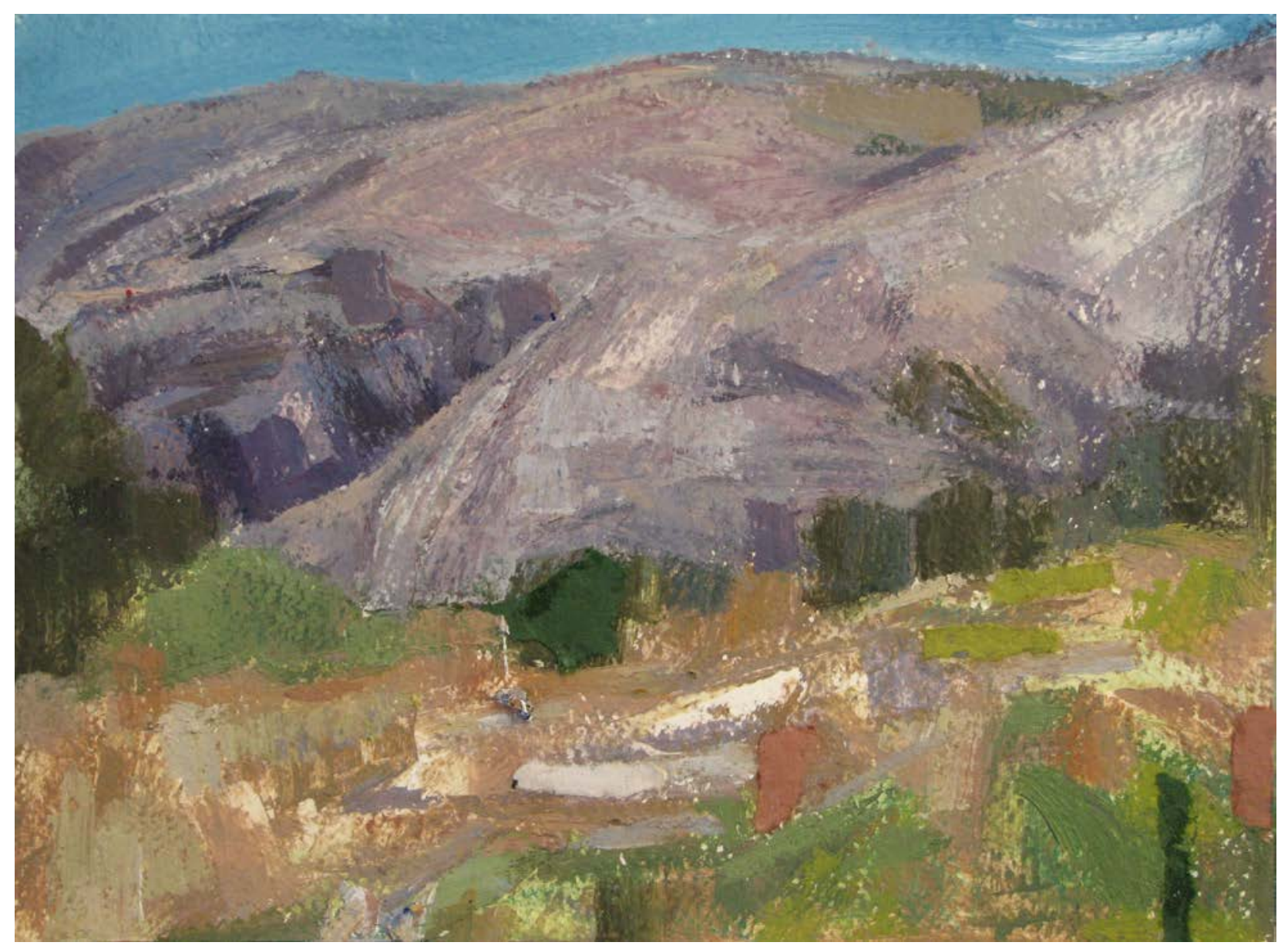

Fuente: Carmen Andreu, Subida a la Maroma.

Temple de huevo sobre papel, 23 x $31 \mathrm{~cm}$. (2011)

En las áreas campiñesas, donde el olivar tenía mayor presencia, era más común encontrar fincas de olivar ordenadas en hileras, cuyo principal aprovechamiento era la producción de aceituna. Sin embargo, también en estos lugares, una parte muy importante de los olivares aparecían como dispersos en el territorio, en fincas de cereal, huertas de regadío y superficies forestales y de pasto (descritos en los catastros como de mala calidad o poco productivos). Se caracterizan como fincas de olivar con muy pocos pies por hectáreas (entre 40 y 50), en las que se combina la producción de aceituna con el aprovechamiento de su cubierta vegetal como pasto. Aunque resulta difícil cuantificar la dimensión de este modelo o sistema de aprovechamiento, parece claro que hasta bien entrado el siglo XIX el olivar más recurrente era un cultivo multifuncional, donde las extracciones de leña podían ser más importantes que la apropiación del fruto, crecía sin orden entre otros tipos de aprovechamientos, los animales pastaban en él, quedando inserto en los cercanos campos del ruedo entre huertas y vides (Infante-Amate, 2014). En el municipio de Baena, paradigma de la 
especialización oleícola andaluza, todavía en 1858, el 40 \% de la superficie de olivar era descrito como "disperso", arrojando producciones de entre 100 y $200 \mathrm{Kg} / \mathrm{ha}$ frente a los que producían $1220 \mathrm{~kg} / \mathrm{ha}$ de la mejor calidad y solo ocupaban un 6 \% del territorio (Infante-Amate, 2014).

De alguna manera, el olivo se presentaba como un paisaje derivado tanto de la dispersión a distancia de la semilla del acebuche que, algunas aves migrantes llevaron a cabo por la frugivoría -método específico de propagación-, como de la "frutalización" del bosque mediterráneo de acebuches por la acción humana domesticadora (González Bernáldez, 1992).Más cercano, por tanto, a la dehesa o al montado, como decíamos arriba.

En el resto de los procesos de colonización agrícola en el Mediterráneo, se han apuntado varias estrategias que distinguen al olivo entre otros cultivos, muchas veces integrados en complejas teselas ya ordenadas, o en sistemas asociativos, en ocasiones de carácter agroforestal (Blondel, 2006). El olivar andaluz que describen las fuentes desde 1750 y en buena parte del siglo XIX o el que todavía aparece en muchos fotogramas del vuelo americano de 1956 y es clasificado como "bosque abierto" o "sabana" por sus primeros fotointérpretes, responde más al manejo agroforestal que al típicamente agrícola.

Figura 5. Superficie ocupada por cada modelo paisajístico de olivar en Andalucía

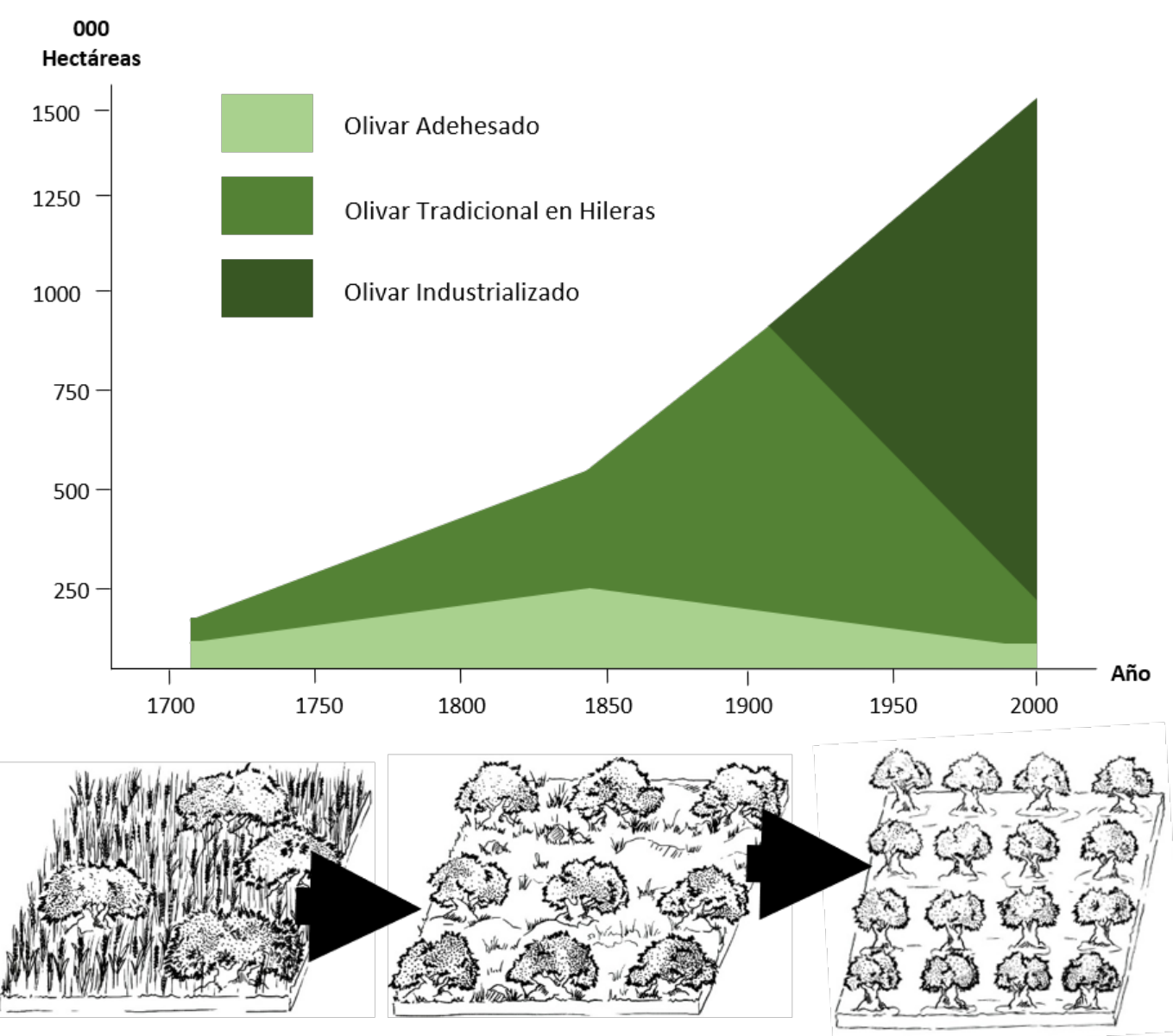

Fuente: Infante-Amate (2014) 


\subsection{Olivares tradicionales progresivamente ordenados}

A lo largo del siglo XIX, como se ha descrito, aumentaba la densidad de población en la región a la vez que caían las trabas institucionales del Antiguo Régimen. La colonización agrícola avanzó y con ella creció la superficie de olivar. Pero, también, tuvo lugar un proceso de intensificación en su laboreo y en sus podas, que, además de requerir más trabajo, se dirigía principalmente a la mejora productiva del fruto. De esta forma, los amillaramientos de finales del siglo XIX evidencian un proceso por el que los olivos dispersos, asociados o con manejos agrosilvopastorales, tienden a desaparecer, abriéndose paso un olivar cada vez más ordenado. Aumentó el número de municipios con olivares en hileras o, dicho de otra forma, con monocultivo olivarero y densidades de pies por hectáreas cada vez mayores.

La creciente demanda de aceite, por un lado, y su carácter multifuncional en contextos de presión poblacional, hacían que los campesinos de la región apostaran por el olivar, labrándolo de manera más intensiva. Un repaso por los testimonios de la época muestra una insistencia en describir al olivo como un cultivo capaz de producir una amplia variedad de productos para el sustento campesino: "Esta planta, pues, es la alegría perenne de nuestros campos; la restauradora de nuestras fuerzas; el alivio inocente del calor, y del frío como combustible; (...) la que ofrece primorosa madera al ebanista; la que suple y repuebla nuestros destruidos y abandonados monte" (Esponera, 1851:4). De manera similar se hacía a finales del siglo XIX: "El aceite es un artículo de primera necesidad para alimento del hombre y como condimento. Sirve también para el alumbrado y otros diferentes usos, como en la medicina, en las artes y en las industrias en que juega un papel importante (...). Sus hojas sirven de alimento al ganado cabrío, de sus orujos se puede extraer gran cantidad de nitrato y carbonato de potasa y mezclado con salvado se emplea para alimento de los cerdos y también de excelente abono. Y por último su madera y sus raíces sirven para la ebanistería, para hacer muebles de lujo y como uno de los mejores combustibles" (Serra, 1878, pp. 466-67). Y todavía en 1924 se subraya aquella percepción en un Congreso Internacional sobre Olivicultura: "Verdad grande la que dice que es el olivo el primero de todos los árboles; todo se puede sacar y todo se puede obtener de él" (Sánchez, 1924, p. 21). Tales comentarios no hacen sino abundar en una realidad ya señalada por Columela o Virgilio en la antigüedad, lo que nos permite subrayar cómo hasta bien entrado el siglo XX, en contextos preindustriales, el olivo mantuvo su carácter de integración productiva, aunque en una transición sistemática evidente hacia la ordenación del plantío (Figura 6).

Las primeras transformaciones intensificadoras del olivar parecen relacionadas con las revoluciones productivas e institucionales del siglo XIX, que se extendieron de manera desigual por todo el territorio andaluz. El mapa correspondiente a 1880 de nuestra Figura 2 nos invita a pensar que en el siglo XIX el olivar agroforestal debió extenderse en la misma o en mayor proporción que el olivar 
ordenado en hileras. Tenemos pruebas de que en municipios de fuerte tradición oleícola (Baena, Osuna...) el olivo adehesado todavía ocupaba la mitad de la superficie en 1858, luego es razonable pensar que ambos modelos avanzaran por igual hasta la mitad del siglo XIX. Para 1900 y en mucha mayor medida a mediados del siglo XX, el olivar disperso, poco productivo y asociado a la ganadería, dejó de ser un aprovechamiento común, hasta el punto de que el que se conserva en tales condiciones parece más fruto del abandono o de la marginalidad (Guzmán, 2005). En 1975, la Estadística Agraria contabilizaba en Andalucía alrededor de 1,7 millones de árboles dispersos, que podrían ocupar, todos juntos, una superficie virtual de 17 mil hectáreas. En esa fecha el olivar en cultivo asociado superaba levemente las 50 mil hectáreas. Sin embargo, la superficie de olivar no asociado ni disperso superaba los 1,2 millones de hectáreas. En otras palabras, la tipología de olivo agroforestal o integrado con otros aprovechamientos tendió a desaparecer a finales del siglo XIX, resultando claramente residual a mediados del XX.

\section{Figura 6. Olivar tradicional andaluz, entre otros cultivos y áreas asilvestradas, o ya ordenado}

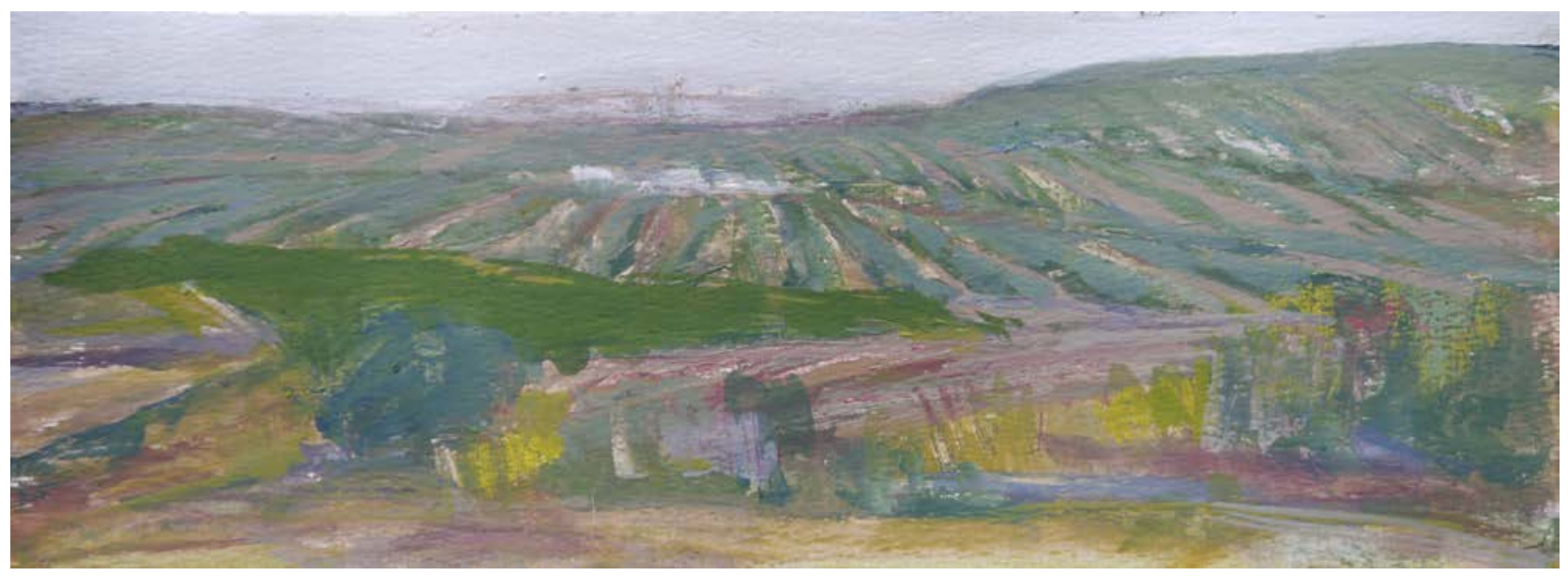

Fuente: Carmen Andreu, Camino de Aznalcázar.

Temple de huevo sobre papel, 15 × $40 \mathrm{~cm}$. (2016)

\subsection{Olivares industrializados y tendentes a la desnaturalización}

La industrialización agrícola, el cambio de funcionalidad productiva y la integración en los mercados globales, dibujan -desde la década de 1960- el proceso de mayor y más acelerada transformación olivarera de la historia, que se habría de extender a la mayoría de los olivares de la región en apenas un par de décadas y que terminó por trastocar sus sistemas de explotación ¿Cuáles han sido los sistemas resultantes de esta era industrial y global? ¿Cómo ha afectado tal cambio a la morfología olivarera?

La adición masiva de fertilizantes químicos, así como la creciente irrigación artificial permitió aumentar la densidad de plantación, impulsando el proceso de cambio quizás más notorio. A fin de 
cuentas, el olivar tradicional, que rara vez recibía fertilización, apenas podía superar producciones de $1000 \mathrm{~kg} / \mathrm{ha}$ en buena medida debido a que tales sistemas de reposición de la fertilidad no podían sostener más de 100 árboles/ha (Naredo, 1981). Entre finales del siglo XIX y la década de 1970, antes de la industrialización del manejo, la densidad se mantuvo bastante estable, en torno a los 90-100 árboles/ha, con obvias divergencias regionales. Sin embargo, desde entonces, el aumento de densidad del arbolado ha sido radical. En Andalucía, en 1972, el 80 \% de los olivares contaban con una densidad menor a 100 árboles/ha., mientras que ya en 2002, se observa una distribución tendente al aumento de los pies por hectárea: Solo el 34 \% de los olivares contaba con menos de 100 árboles/ha, siendo el resto mucho más denso, de manera que casi 150 mil hectáreas ya tenían más de 200 árboles/ha (Figura 7).

Figura 7. Superficies de olivar en Andalucía (miles de hectáreas) según pies por hectárea en 1972 y 2002 (a) y superficie irrigada (miles de hectáreas eje de la derecha)

\section{y árboles diseminados (miles de pies, eje de la izquierda) (b)}
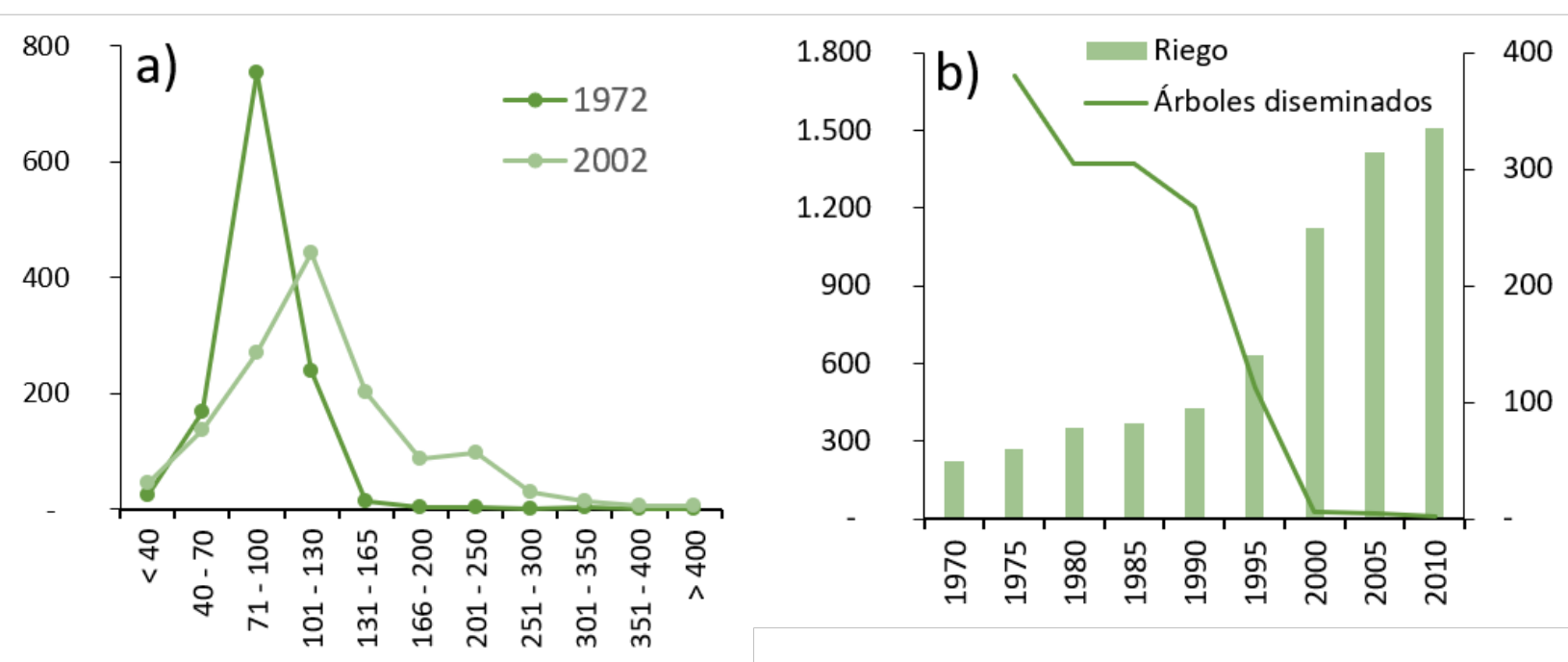

Fuente: para 1972, Ministerio de Agricultura, Pesca y Alimentación (1975);

y para 2002, Junta de Andalucía (2002)

Si la industrialización agrícola trajo un aumento de la densidad de plantación, la creciente mercantilización del cultivo y la política de subvenciones de la PAC - que asoció ayudas a mayores niveles productivos - terminaron por hacer desaparecer los modelos de olivar menos productivos en términos de aceite: se observa una total desaparición de los árboles dispersos, así como del cultivo asociado. En la figura 7 también se muestra la evolución de los árboles de olivo dispersos según las estimaciones de las Estadísticas Agrarias: pasaron de 1,7 millones en 1975, a poco más de medio millón en 1995, hasta su total desaparición en la actualidad, cuando solo se contabiliza apenas 10 mil árboles. 
Existen otros fenómenos reseñables del cambio de los últimos años: El primero está asociado a la creciente utilización de maquinaria agrícola o tratamientos químicos en el manejo de la cubierta vegetal. Si en sistemas tradicionales era difícil eliminar la vegetación espontánea durante la mayor parte del año, hoy, las tecnologías disponibles hacen que buena parte de los olivares de la región apliquen manejos muy intensivos que terminan por eliminar completamente la vegetación, desnudando totalmente sus parcelas (Vanwalleghem et al., 2011; Lima Cueto et al., 2017).

Pero, además, en el actual paradigma medioambiental, comienzan a observarse y a proliferar nuevos modelos de manejo y sistemas de explotación. Así, en apenas 10 años han pasado de ser inexistentes a ocupar unas 50 mil hectáreas tanto el olivar superintensivo como el llamado olivar orgánico-moderno. El primer caso es un modelo de olivar en seto con densidades de plantación que pueden superar los 4000 pies/ha, semejante al cultivo intensivo de la vid, donde el árbol es sustituido por varios arbustos dispuestos en espaldera. El olivar orgánico-moderno, por diferenciarlo del orgánico tradicional descrito hasta ahora en estas páginas, también está aumentando en superficie y buena parte del mismo recupera manejos tradicionales - proliferación de cubiertas, integración con ganado...- aunque, por otra parte, simplemente aparece como un modelo orgánico intensivo de sustitución de insumos (Guzmán, 2011). La superficie de ambos es aún residual sobre el total del olivar andaluz y habrá que esperar más tiempo para analizar la dimensión real de su significación.

\section{Claves paisajísticas del olivar: de acebuchales a paisajes despensas y a fábricas de aceite con nombre propio}

¿Cuándo se convierten en paisajes estos territorios del olivar, que acabamos de reconocer y diferenciar? Cuando media la emoción y se produce la interacción necesaria entre el sujeto que percibe y el objeto que es percibido. Intentaremos ahora interpretar estos variopintos y ricos paisajes del olivar mediante una lectura transdisciplinar y hermenéutica que nos permita sintetizar, comprender y comunicar - por medio del lenguaje común y de la imagen creativa- una realidad compleja. Esperamos que la mezcla de datos contrastados y categorizados de estos paisajes del olivar andaluz con nuestro contacto directo y compartido con los mismos nos vaya proporcionando no sólo información (análisis), sino también conocimiento (comprensión) y sabiduría (valoración estética), para que todo ello nos conduzca a un compromiso transmisible de copertenencia (ética), de manera que tales paisajes se vayan convirtiendo en realidades trayectivas o mediales entre lo objetivo subjetivado y lo subjetivo objetivado (unas especies de yin-yang, según sus orígenes taoístas). Vayamos leyendo hermenéuticamente (componentes, atributos, núcleo de significado) las manifestaciones paisajísticas actuales del olivar andaluz, que se constituyen en testimonios de los distintos procesos históricos o marcos vitales que se han descrito y cuyos respectivos valores están siendo puestos en evidencia por miradas identitarias y creativas que cofabrican el acervo cultural 
desde el que pueden comprenderse como paisajes y ser considerados y reconocidos patrimonios mundiales.

\subsection{Olivares primitivos: desde dispersos entre matorrales y cultivos hasta adehesados}

4.1.1 Paisaje de matorral noble con la presencia de acebuches arbustivos

a) Componentes principales

Matorral mediterráneo o maquis con presencia salteada de árboles entre los que aparece o destaca el acebuche.

Figura 8. Acebuches arbustivos y salteados en el matorral

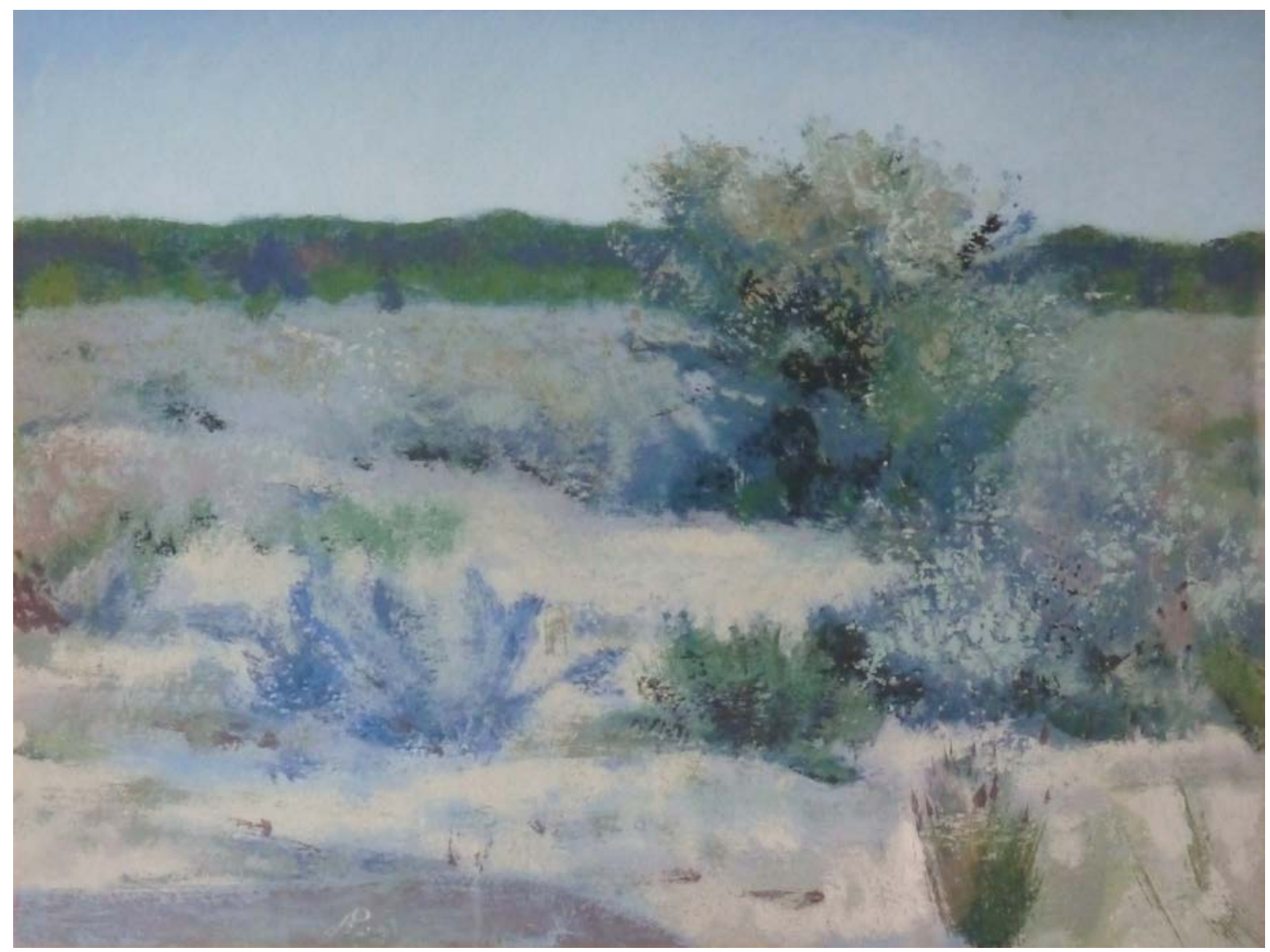

Fuente: Adolfo Piche. Pastel sobre papel (1989)

b) Atributos

Hitos verdes permanentes rodeados de transformaciones cromáticas estacionales, biodiversidad evidente, área asilvestrada que atrae pájaros y es origen de la frugivoría (Figura 8).

c) Núcleo de sentido

"Es característica de las partes costeras de la vegetación mediterránea la maquia o comunidad preforestal, vestigio del antiguo bosque, donde dominan especies como el acebuche, el algarrobo, la encina, las pistacias, etc." (González Bernáldez, 1992, p. 136) 
4.1.2 Acebuchales pioneros entre las herrizas y a veces monumentales

a) Componentes principales

Acebuches arbustivos o arbóreos, que soportan adaptaciones a situaciones limitantes y se convierten en signos de vida vegetal allí donde no abunda, o de naturaleza silvestre, allí donde está muy domesticada - herrizas entre las tierras cultivadas de las campiñas altas-. También acebuches que han ido adquiriendo potencia arbórea y son hitos identificadores o monumentos naturales de lugares concretos (Figura 9).

Figura 9. Acebuches aislados en herrizas de las campiñas altas y acebuche abanderado por el viento
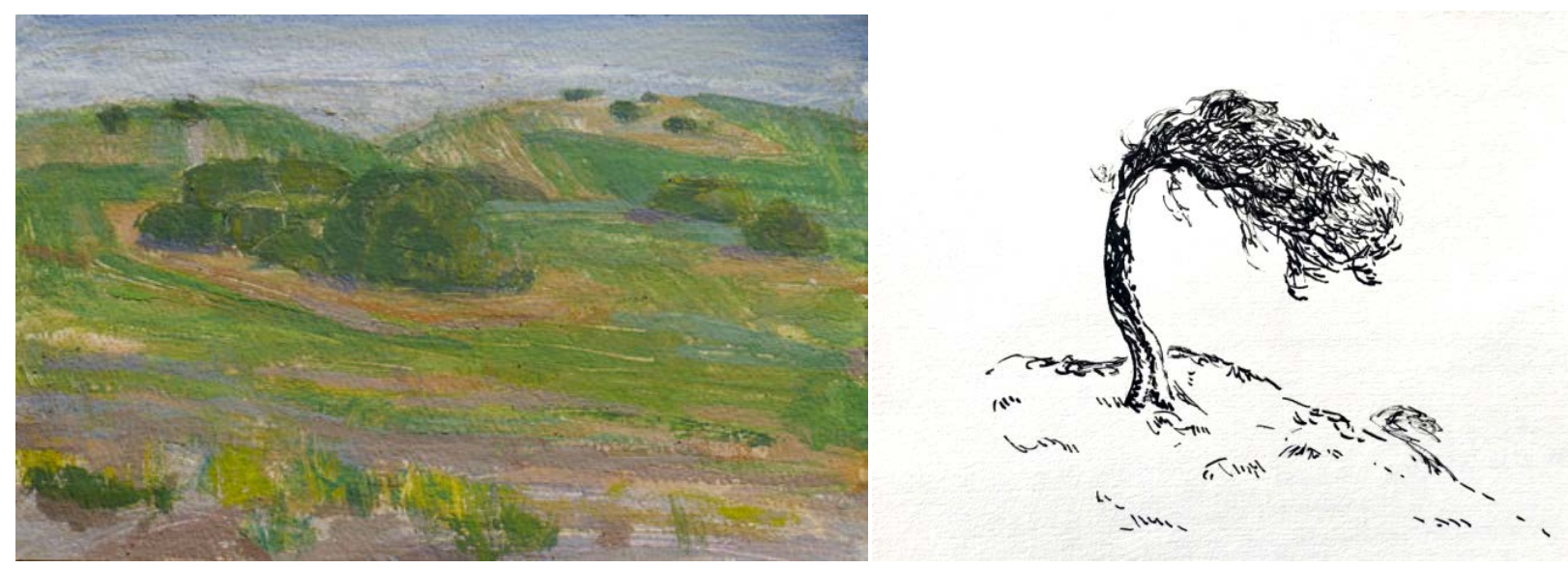

Fuente: Carmen Andreu. Enigmas en el paisaje.

Temple de huevo sobre papel. 23 x 15 cm. (2012) Tinta sobre papel (2017)

b) Atributos

Capacidad de adaptación y belleza arbórea. Enigmas de silvestre libertad entre los ordenados cultivos. Monumentalidad, simbolizaciones populares y reconocimientos institucionales.

c) Núcleo de sentido

El acebuche es un arbusto ancestral y muy mediterráneo, cuyos ejemplares andaluces más hermosos se encuentran al sur del sur. Allí, cerca de África, aparece un rico mosaico de confluencias de redes de vida y de cultura. La influencia árida del cercano Sahara se atempera con el soplo de los vientos oceánicos de poniente, cuyas humedades se concentran en las sierras del Retín, la Plata y el Aljibe. Allí, en las margas y conglomerados de una atormentada geomorfología de flych, encuentra el acebuche suelos propicios que generan ejemplares muy bellos, cuyos troncos sostienen copas de ramas muy flexibles que tienden a orientarse o abanderarse en la dirección de los vientos dominantes... Por el estrecho pasan los barcos de fenicios y griegos, cuyos 
conocimientos han ido convirtiendo el acebuche en un cultivo para el aceite que comenzará a lubricar las rutas comerciales y culinaria (Delgado Bujalance, 2011, p. 7).

\subsubsection{Dehesas de acebuche}

a) Componentes principales

Acebuches arbóreos ahuecados y conformando dehesas, en las que se mezclan con pastos y con matorrales diversos (Figura 10).

\section{Figura 10. Dehesas de acebuche}
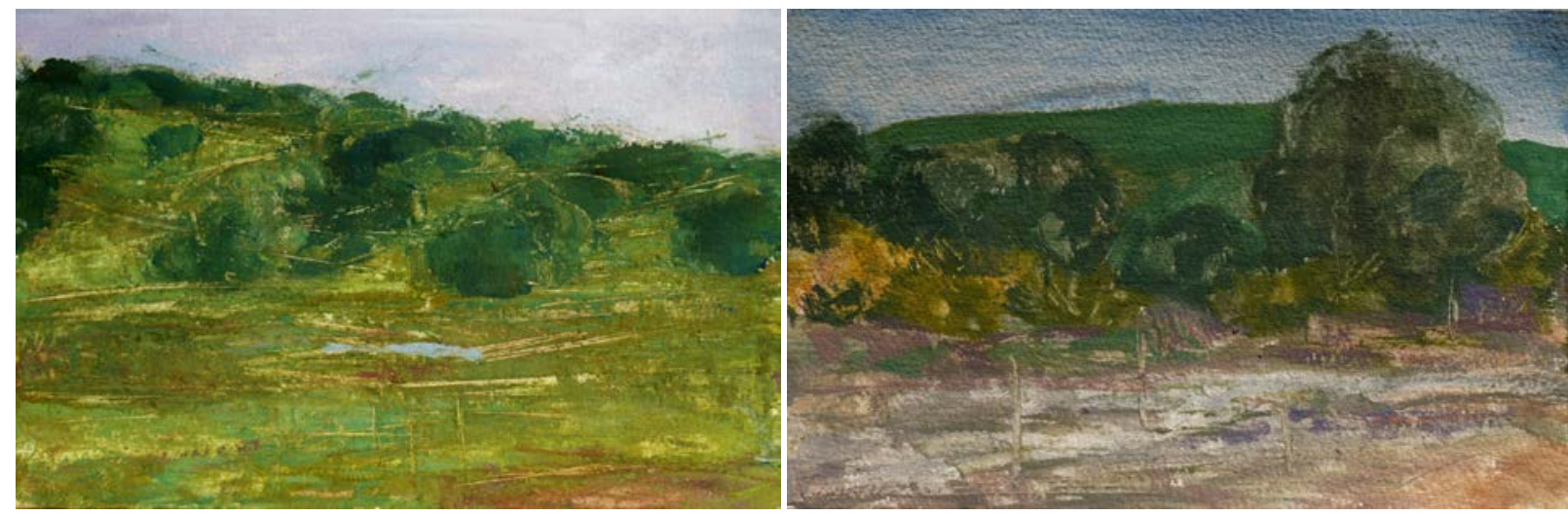

Fuente: C. Andreu. Temple de huevo sobre papel. 15 × 23 cm. (c.u.) (2012)

b) Atributos

Bosque abierto mediterráneo, perennifolio colorista y sonoro. Sotobosque muy variopinto y presencia ostensible de vida animal silvestre (conejos, jabalíes, perdices, tórtolas, cigüeñas...) y doméstica (vacunos, caprinos, ovinos y equinos). A veces, escenarios festivos y/o sagrados.

c) Núcleos de sentido

Acebuchal adehesado. "El acebuchal, adehesado e instalado en colinas que ceden generosas el agua a charcas y lagunas cercanas, acoge no sólo a vacunos sino también a cigüeñas, garcillas, garzas y patos... y se hermana con el lentisco para dar cobijo al conejo o con el palmito para ofrecer en sus proximidades el alegre correteo de la perdiz roja española" (Andreu, 2012). ${ }^{3}$

\subsection{Olivares tradicionales progresivamente ordenados}

4.2.1 Olivar sin marquilla, procedente de injerto en acebuche

a) Componentes principales

Mezcla de olivos salteados y alineados en piedemontes, terrazas y caserías serranas (Figura 11).

3 Comentarios de C. Andreu a sus pinturas. 


\section{Figura 11. Olivos salteados y adehesados en una ladera y en una casería serrana}
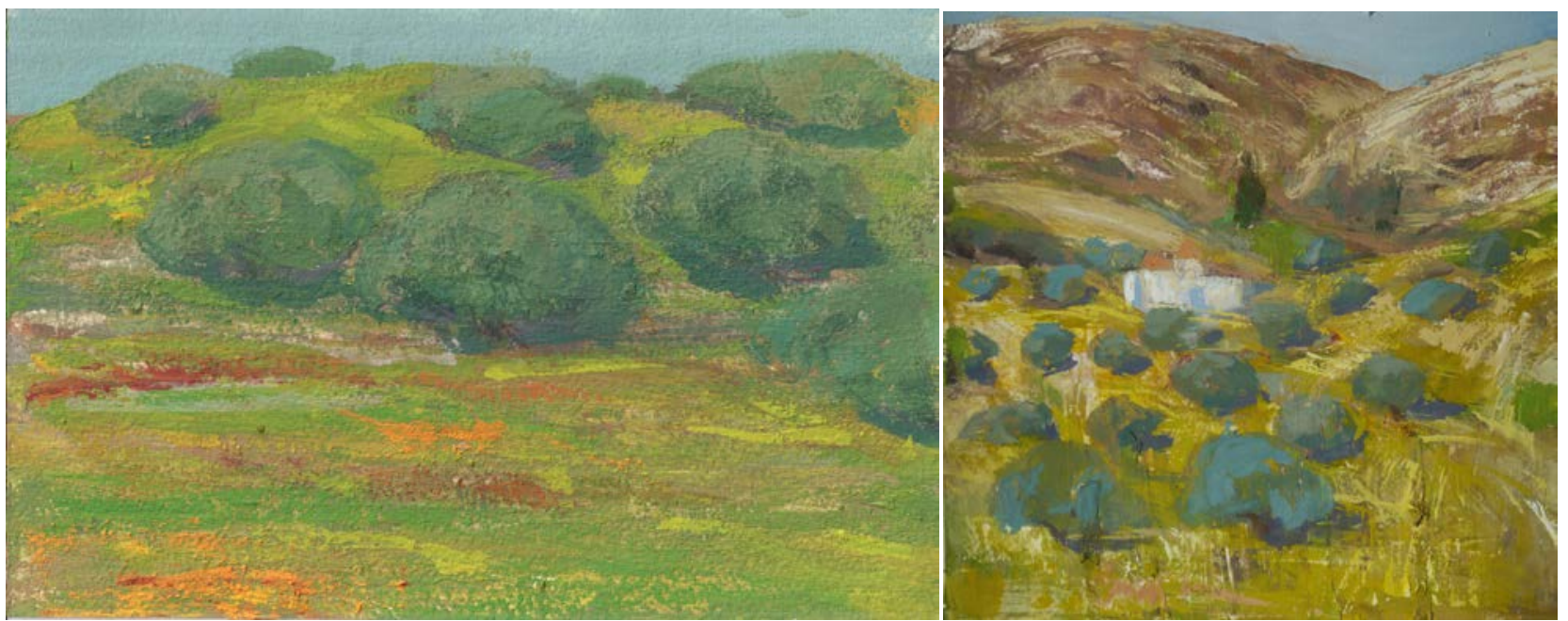

Fuente: Carmen Andreu. Temples de huevo sobre papel.

$15 \times 23 \mathrm{~cm}$. y $30 \times 30 \mathrm{~cm}(2016)$

b) Atributos

Calificados por los intérpretes americanos de sus primeras fotos aéreas (1956) como bosques abiertos o ahuecados: sabanas o dehesas (González Bernáldez, 1992). Escasas productividades.

c) Núcleo de sentido

Todavía en medio de los ordenados olivares de hoy, sobresalen a veces restos de olivos viejos de casta distinta, lechines, manzanillos, injertos algunos en acebuches por las cercanías de montes y cañadas, rebajados otros, hijos de mala madre, sin orden en su conjunto, tan libres, altivos y desgreñado, tan pródigos y llenos de poesía, bailadores eternos en el campo, de un verde jugoso, con cuerpo y sombra de árboles con acogimiento a su pie para caminantes, con menos aceitunas y más leyenda que estas diligentes filas de hojiblancos que no se acaban y a quienes no detienen más que las peñas en la herrizas y los limos de los ríos donde llegan a correr. Eran aquellos olivos de molino de viga, con largos husillos de ciprés o nogal, manejados por poco más que maestro y cagarranche que duraban lo que Dios quería, porque no eran tiempos de prisa, como acomoda a los olivos que maldito el caso que hacen del tiempo (Muñoz Rojas, 2006, pp. 167-168).

\subsubsection{Olivar campesino tradicional}

a) Componentes principales

Acebuches, olivos sueltos y olivar es de los ruedos (Figura 12), que ocupan parcelas pequeñas y multifuncionales en las que se mezclan con viñedos, frutales y sembradíos o enfilados como setos protectores de vientos en minúsculas propiedades. 


\section{Figura 12. Acebuches y olivos en ruedos}

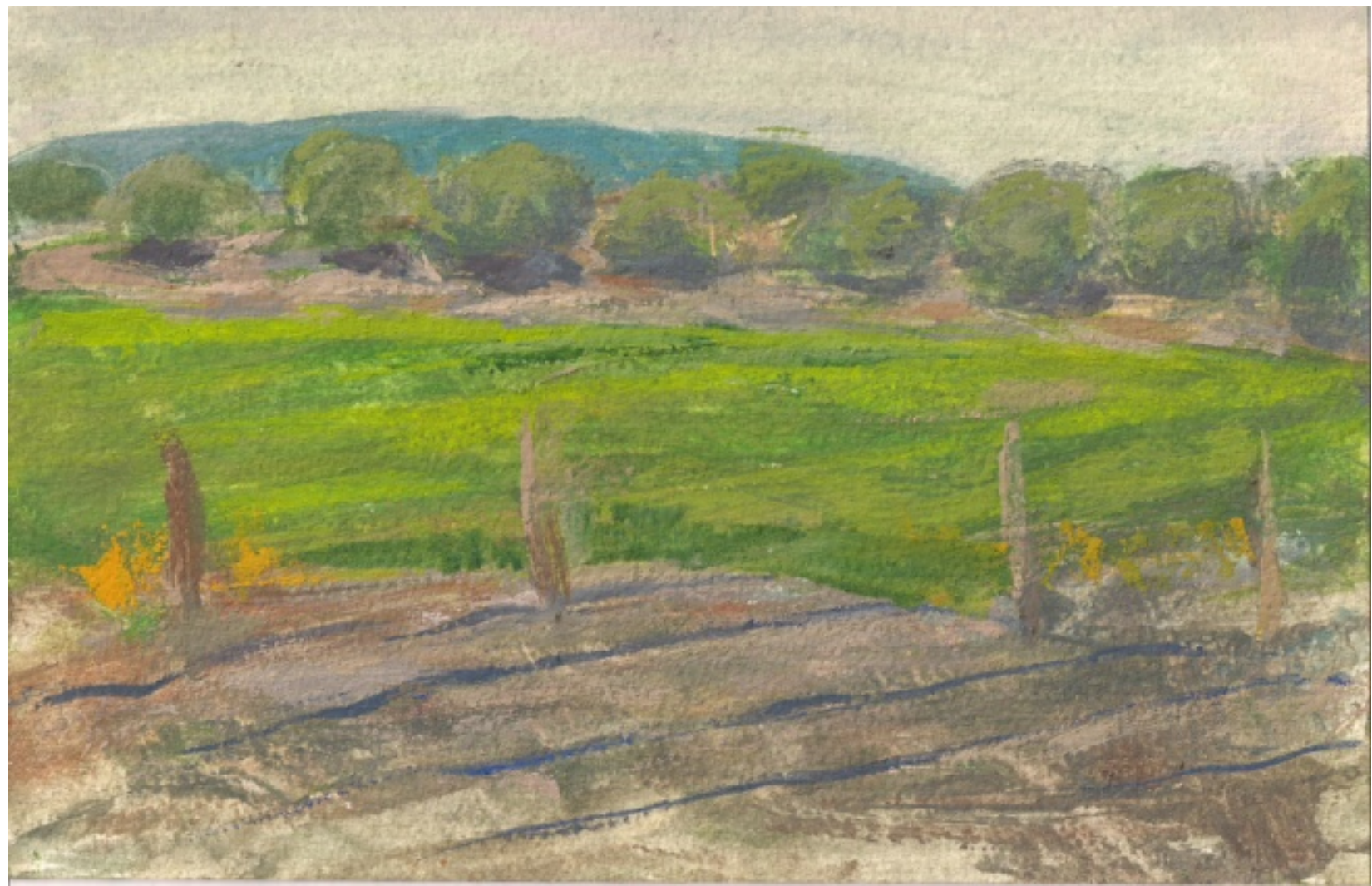

Fuente: C. Andreu, Ruedo de Estepa. Temple de huevo sobre papel 13 x 24 cm (2011)

\section{b) Atributos}

El olivo multifuncional como despensa que garantiza aceite, aceitunas, ramón, leña, varetas para encañe y cestería, caza, y cobertura vegetal para el huerto... como cultura, ligado a la vida y la gastronomía cotidiana. El olivo que protege del poder desecante del viento a los pequeños huertos sabiamente ubicados por los agricultores.

c) Núcleo de sentido

Olivos en los ruedos. "Es la cercanía, la vecindad, la que explica la mezcla domesticada y promiscua de los ruedos mediterráneos, en los que portal-enramada-pozo-parra-alberca-huerta-olivofrutal-viña constituyen un todo, que suma herencias y testamentos y sabe tanto de riñas y disputas como de juergas y disfrutes. Estos paisajes híbridos y armoniosos de muchos ruedos, por los que siempre se pasa con prisas, merecen un tiempo más lento que permita admirarlos y disfrutar con ellos" (Ojeda, 2002, p. 11).

4.2.3 Olivar de sierra, colonizador de laderas y de altiplanos limitantes

a) Componentes principales

Olivos trepando afanosos por laderas y ocupando baldíos y antiguos comunales con blancos caseríos dispersos y ocasionales (Figura 13). 


\section{Figura 13. Parcelas de olivar en sierra y olivares trepando por laderas de calizas devónicas}
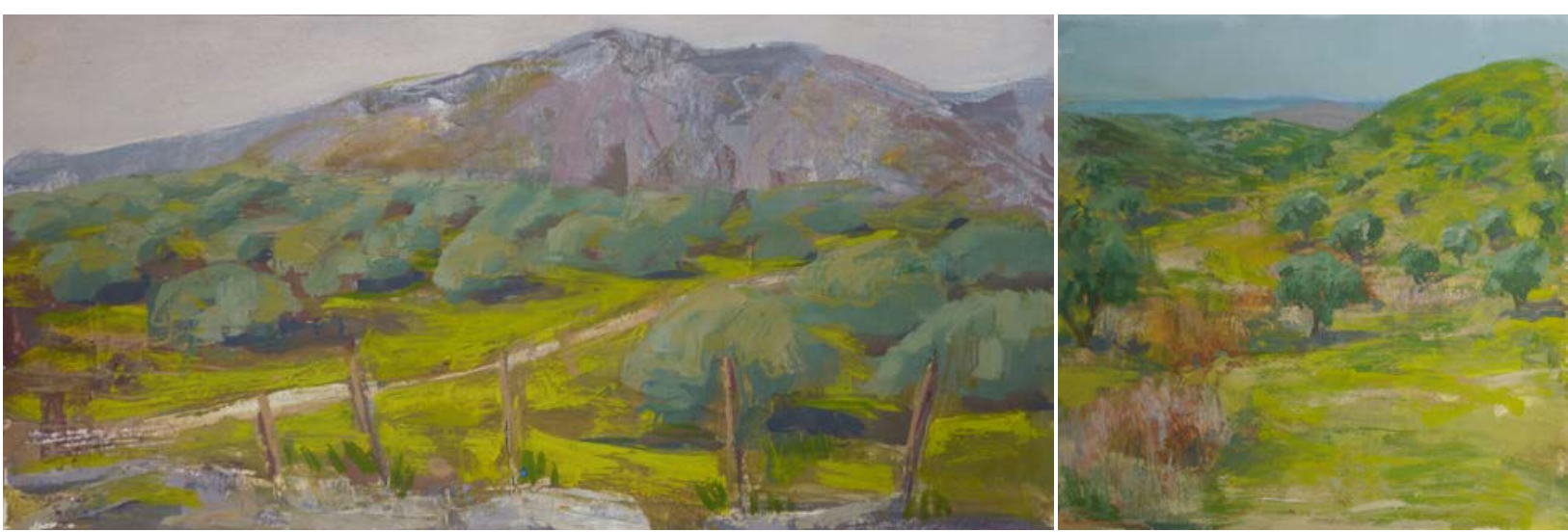

Fuente: Carmen Andreu, Temples de huevo sobre papel.

$15 \times 40 \mathrm{~cm}$. y $40 \times 40 \mathrm{~cm}$. (2016)

\section{b) Atributos}

Mar de olivos que baja desde la sierra o escala flotantes colinas, humo, signos de ciclos de vida y de liturgia campesina.

c) Núcleo de sentido

Idilio mediterráneo. Amanece como un océano de aire y cristal transparente, vemos como la inversión térmica de estas primeras horas de la mañana genera distintos planos y refracciones sobre aquellas transparencias, La sensación es íntima y polisensorial. El vacío se va llenando de plenitud: Hasta el fondo hileras de olivos que convergen en el horizonte sobre suelos rojizos y en los primeros planos olivos sobre cuyas ramas cuelgan hojas como párpados a las que un sueño pesado, casi insoportable, hace caer sobre el aire y, vencidas por el propio peso del sueño, se mecen lentamente. Sus pestañas rayan el aire. Emerge la belleza como ejemplo del bien platónico, que la mezcla y vincula con bondad y armonía. Pero en el olivar también hay vida que amanece: Brilla la lumbre de las candelas; huele a ramón quemado; se oyen voces, afanes y trabajos buscando una buena cosecha; mucho trabajo que delata el humo. Al fondo, el sonido de un tractor ¡cuidado con la modernidad, indolente y metonímica! (Delgado Bujalance, en Cazorla, 11 de marzo de 2011, a las 07,30 horas). 
Figura 14. Olivar diverso con cobertura vegetal

en compañía de otros cultivos y setos silvestres

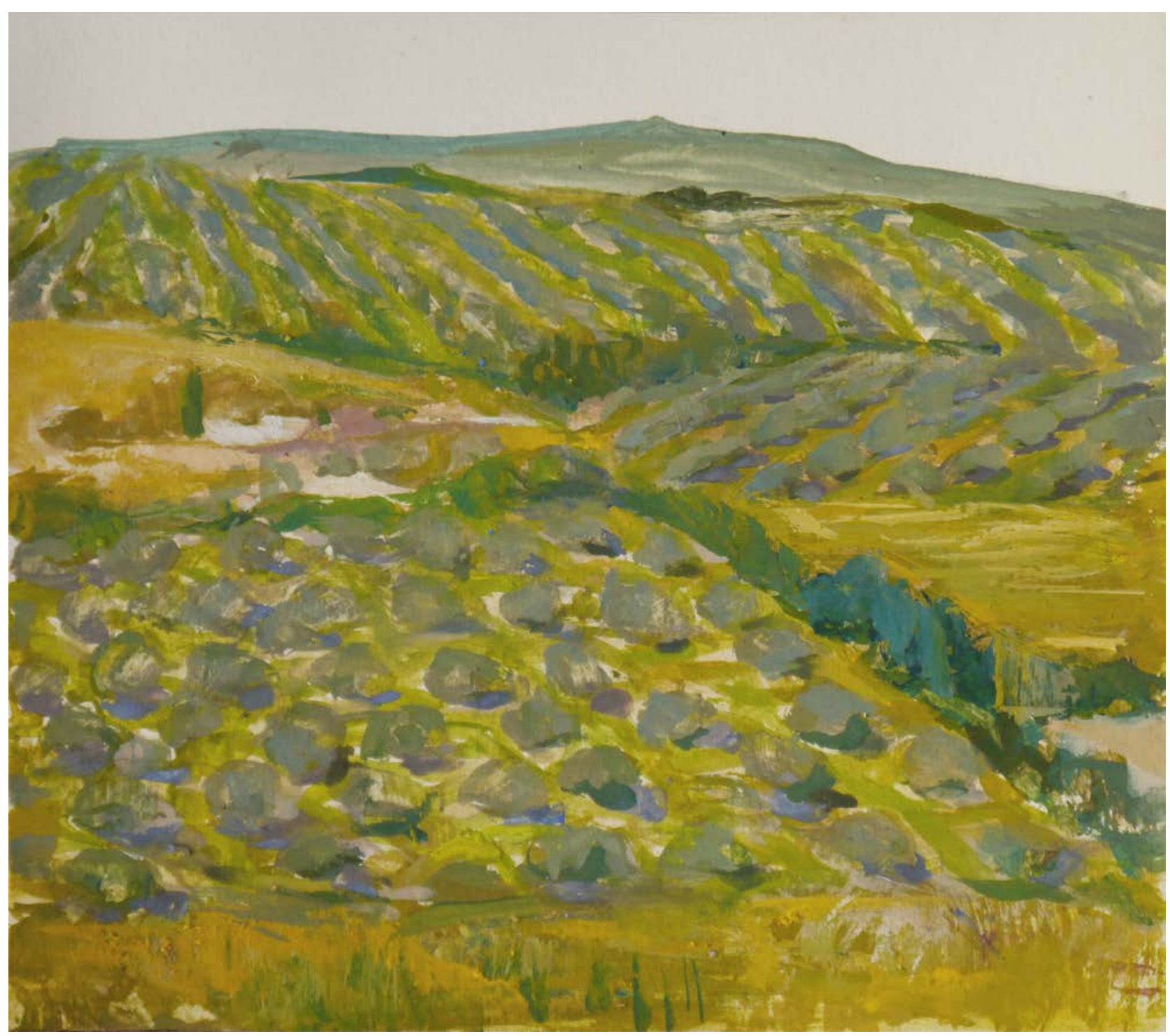

Fuente: Carmen Andreu, Idilio mediterráneo.

Temple de huevo sobre papel, $20 \times 20 \mathrm{~cm}$. (2016)

\subsection{Olivares industrializados}

4.3.1 Olivar moderno adaptado al mercado: Explotaciones monoproductivas (haciendas, caserías, molinos y cortijos de olivar)

a) Componentes principales

Gran finca de olivos ordenados, con edificio multifuncional y sotobosque variopinto y rico en frutos recolectables y en caza menor (Figura 15). 


\section{Figura 15. Olivar centenario en una hacienda del Aljarafe}

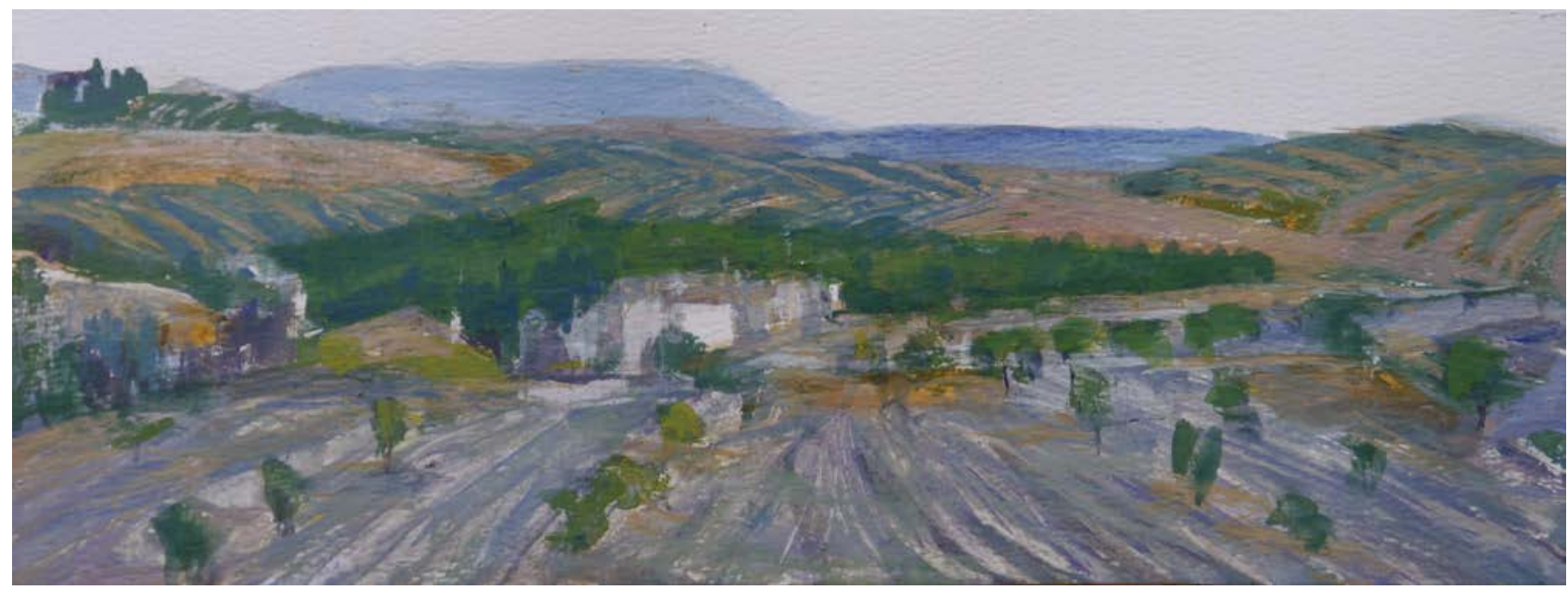

Fuente: Carmen Andreu, Caserío, huerta y olivar. 15 x 40 cm. (2012)

b) Atributos

Expresión del ascenso de la burguesía agrícola, mercado del aceite, complejo agroindustrial, residencia de recreo y exhibición de la clase terrateniente, dominante y urbana.

c) Núcleo de sentido

La hacienda de olivar es ante todo un producto urbano, cuya aparición está insoslayablemente ligada al desarrollo de la metrópolis sevillana...Así, la función agroindustrial de la hacienda, continuadora directa de la llevada a cabo en las antiguas heredades bajomedievales, llega a su momento de máximo desarrollo en las fechas en que la producción aceitera alcanza sus cotas más elevadas, impulsada por la demanda de un ávido mercado urbano que exige un aprovisionamiento a gran escala... Desde que los grupos sociales más encumbrados se hacen cargo de la gestión de sus explotaciones, además de servir como complejo agro-industrial, la hacienda pasa a convertirse en residencia secundaria para sus propietarios, los cuales, al tiempo que acuden a controlar las faenas de producción, aprovechan la ocasión para descansar y recrearse en el campo, acompañados de su cohorte de familiares y amigos y alejados del ajetreo de la ciudad...

...Los molinos, caserías y cortijos de olivar, cordobeses, malagueños, jiennenses y gaditanos son casas rurales que, si bien están cuidadas en su conjunto, presentan una general sencillez arquitectónica, se disponen como edificios de dimensiones medias o grandes con todas sus dependencias organizadas en torno a patios interiores completamente cerrados, cuentan como piezas fundamentales con un molino aceitero y su correspondiente bodega, a las que añaden algunas cuadras para el ganado de labor 
y diversas habitaciones de estancia para los trabajadores y, en la mayoría de las ocasiones, acogen una vivienda, de mayor o menor calidad según los casos, reservada para los propietarios (Florido Trujillo, 1996, pp. 104-126).

4.3.2 Olivar contemporáneo con corrección de la vecería: fábrica de aceite desnaturalizada

a) Componentes principales

Regadío, herbicidas y sotobosque limpio y desnudo. Erosión. Plantación superintensiva. Olivos enanos. Poda en espaldera.

b) Atributos

De explotación agrícola a fábrica de aceite monoproductiva y con nombre propio. Mecanización total. Invasión de tierras muy fértiles y posible "burbuja olivarera".

c) Núcleo de sentido

Paisajes de la geometría, que evidencian con descaro el control del hombre sobre la tierra. Un mundo lineal y dominado, de orden y repetición, retícula de ojos verdes con sabor amargo:

Figura 16. El olivar lineal y subyugado

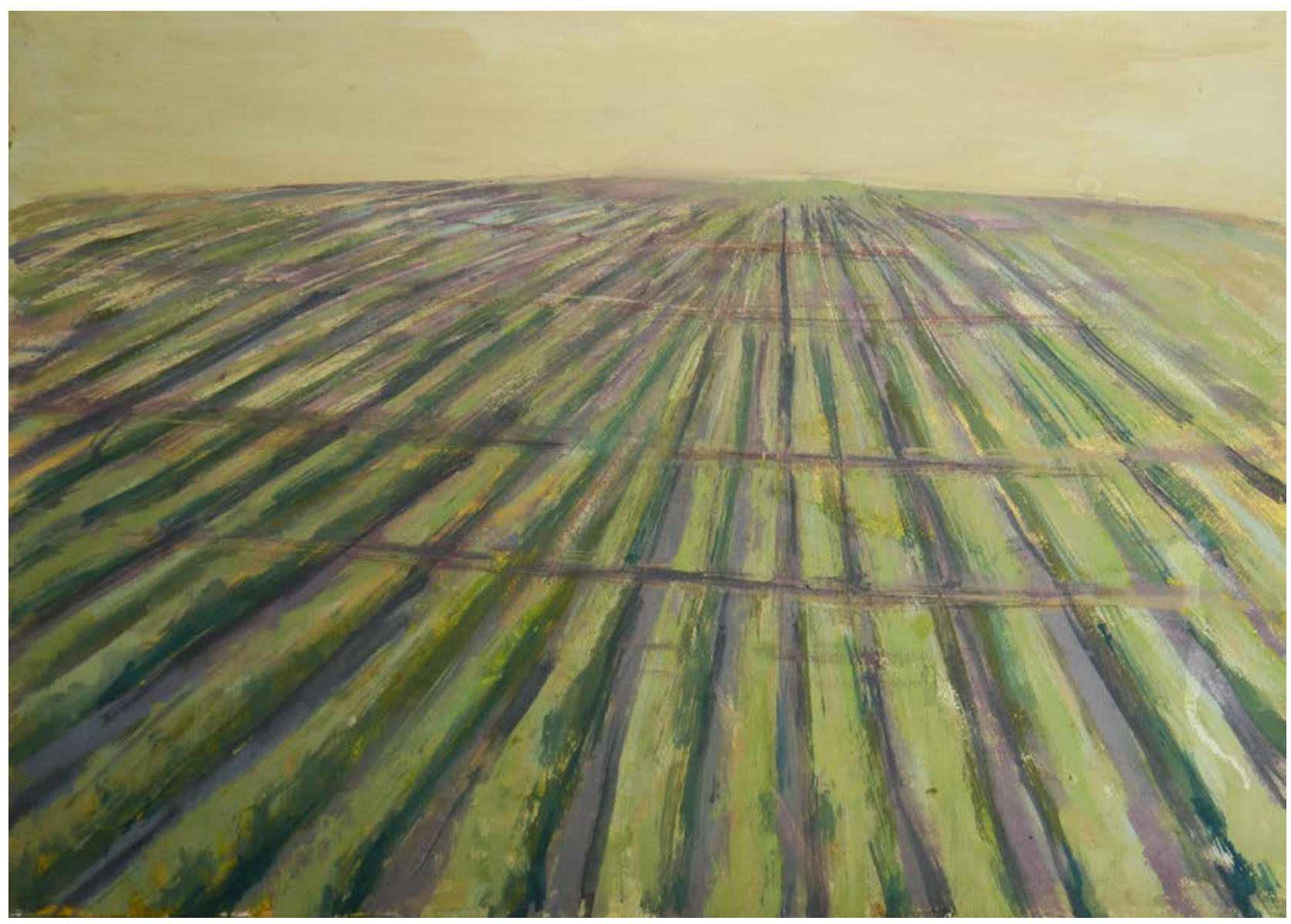

Fuente: C. Andreu, Amarga geometría.

Temple de huevo sobre papel, $30 \times 40 \mathrm{~cm}$. (2016) 


\section{Ecología y realidad del paisaje olivarero andaluz}

Figura 17. Momentos y procesos visibles de la genealogía del paisaje del olivar

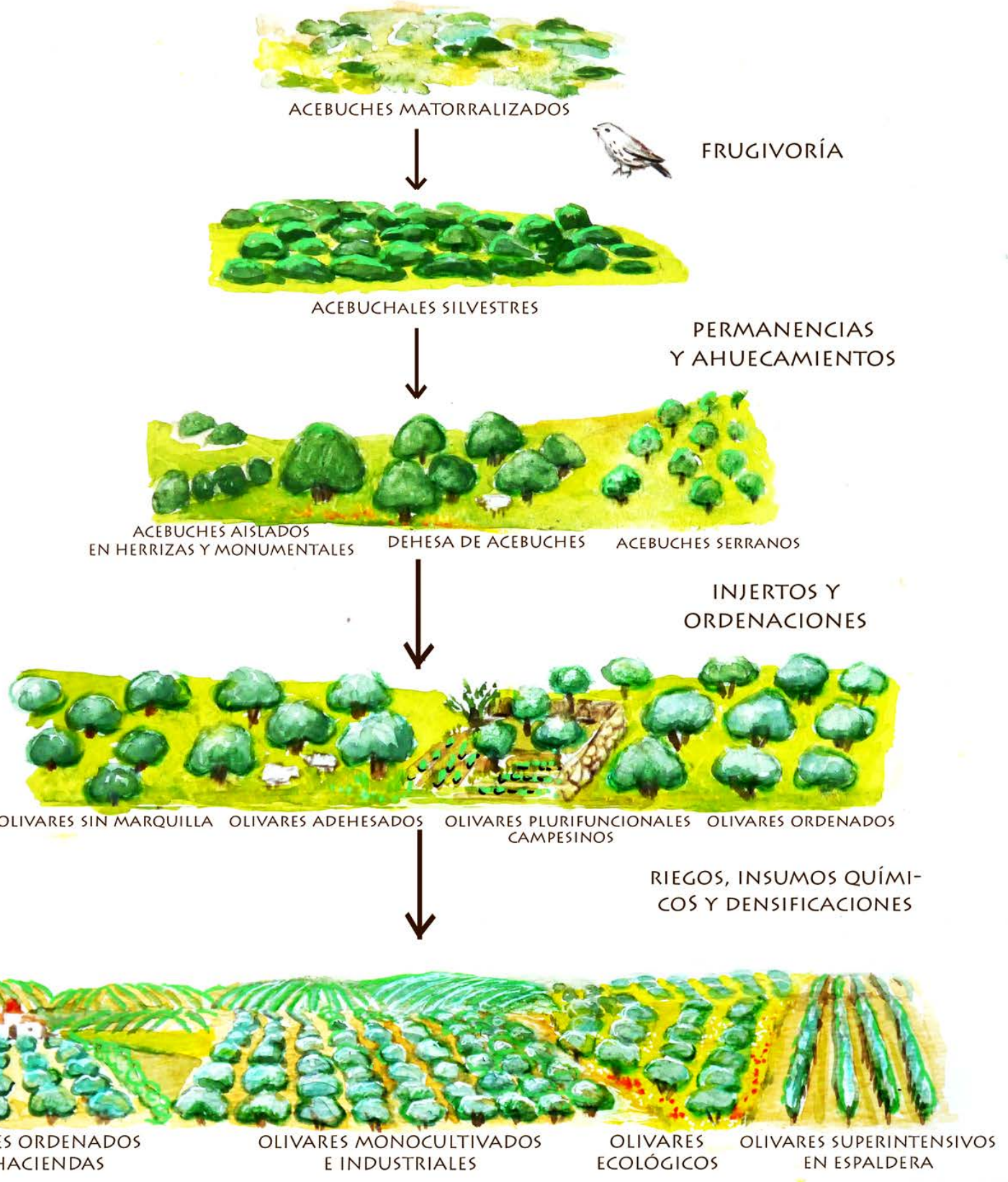

Fuente: Andreu, Infante-Amate \& Ojeda (2016): Resultado del diálogo transdisciplinar

A lo largo de este texto hemos tratado de evidenciar que la excepcionalidad de los paisajes andaluces de olivar que justifica su inclusión en la lisła de Patrimonio Mundial de la UNESCO, que no sólo se sustenta en su formidable dimensión -mayor concentración arbórea del continente europeo- sino también en la milenaria relevancia que este cultivo y sus frutos han ido adquiriendo en el vivir diario y en las culturas de los distintos pobladores mediterráneos: partes esenciales de 
sus dietas, fuente de sus energías, componente básico de sus medicamentos y afeites, ungüento de engrase de sus maquinarias, protagonista de sus obras artísticas, óleo santo de sus cultos religiosos, símbolo de la paz. Las distintas funcionalidades y adaptaciones históricas y geográficas de manejos y paisajes del olivar hablan de la complejidad del árbol y de sabias y elaboradas respuestas a necesidades en este territorio mediterráneo; sabidurías que no se limitaron al marco del mare nostrum, porque su carácter pionero como cultivo comercial ha ofrecido rentas derivadas de la exportación de sus productos, cruzando los mares para llegar a mercados lejanos. De manera que el olivo, sus productos y sus paisajes se constituyen hoy en ejemplo de repositorio de conocimientos agroecológicos, artesano-industriales y estético-simbólicos de la región mediterránea y de su identidad. Nuestro diálogo interdisciplinar nos ha permitido llegar a la síntesis transdisciplinar de la Figura 17.

Pero también hemos mostrado cómo en las últimas décadas las exigencias del mercado han ido conduciendo a una intensificación del cultivo por la vía de la industrialización de sus manejos. La mecanización y la adición no sólo de agua sino de otros insumos externos de origen inorgánico han conseguido romper la tradicional vecería de un árbol vegetativamente problemático por su metabolismo del potasio. Tal respuesta a las necesidades de un mercado expansivo y de periodicidad inflexible, ha ido conduciendo a cuestionables manejos y gestiones de aquellos bellos e identitarios paisajes y marcándolos con indeseados efectos:

- Aumento de los procesos erosivos en un contexto mediterráneo -ya proverbialmente castigado al respecto por su geomorfología y su irregular climatología- pero en el que tanto el acebuchal como el olivar jugaron y deben seguir jugando una marcada función de sostenedores de laderas y colinas, en vez de convertirse en promotores de cárcavas, de pérdidas de suelo fértil y de desertificaciones. Se documentan pérdidas de casi 90 toneladas por hectárea y año, muy superiores a cualquier nivel sostenible de pérdida de suelo (Vanwalleghem et al., 2011).

- Ostensible pérdida de biodiversidad en unos olivares que - por la adición de productos químicos- se quedan desnudos, sin su variopinta cubierta vegetal y dejan de ser sustanciales biotopos de una diversificada flora y fauna silvestre (Muñoz-Cobo et al., 2001; Foraster, 2016).

Los dos efectos negativos anteriores se producen por la intensificación del manejo para multiplicar las productividades (la media productiva española en 1890 era de poco más de 1000 kg de aceituna por hectárea, mientras que hoy se acerca a los $4000 \mathrm{~kg}$ ), así como para reducir la mano de obra (en tareas preparatorias la demanda ha caído de unos 15-25 jornales de trabajo al año a los actuales 3-4 jornales) (Infante-Amate, 2014) Esto es, ha aumentado la productividad de la tierra y de la mano de obra. En menos superficie y con menor esfuerzo, el hombre es capaz de extraer 
muchos más frutos de la naturaleza, lo que de alguna manera puede y debe leerse como un éxito económico-social. Sin embargo, al igual que ocurre con otros cultivos y con otras muchas actividades económicas, el proceso de industrialización acelerada que ha tenido lugar en la segunda mitad del siglo XX, que incluso ha derivado en el nacimiento de una nueva era geológica (el Antropoceno), ha estado acompañado de grandes posibilidades de desarrollo pero también está detrás de múltiples amenazas para el futuro del sector (Beaufoy, 2001, Gómez, 2009; Guzmán, 2011; Foraster, 2016).

\section{Figura 18. Desnudez, intemperie, erosión y pérdida de biodiversidad}
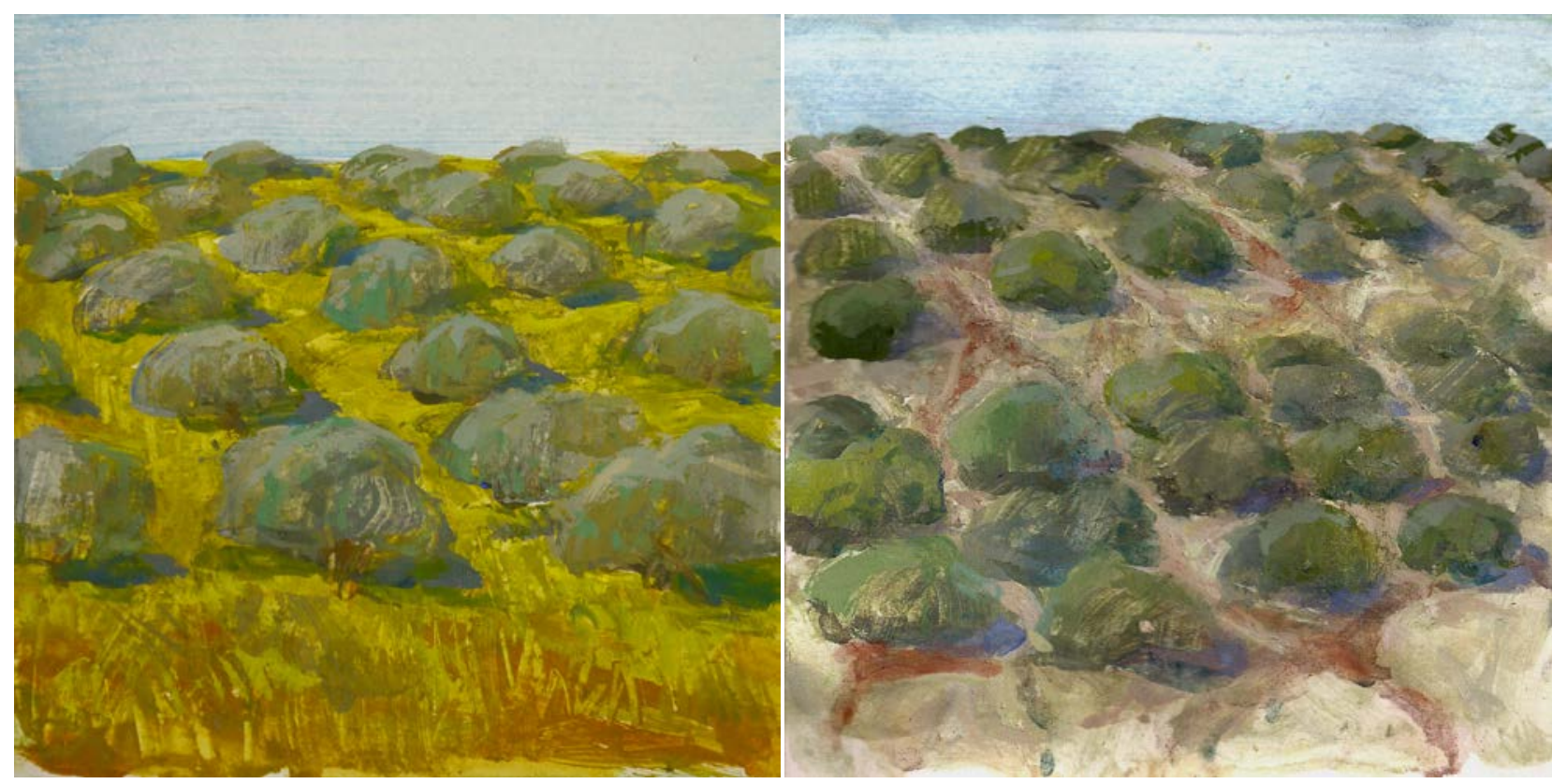

Fuente: Carmen Andreu, Las buenas malashierbas.

Temple de huevo sobre papel. 20 × 20 cm (c.u.) (2016)

Por otra parte, que este masivo e intensificado olivar andaluz - que ha sido ya incluido en una lista tentativa de Patrimonio de la Humanidad de la UNESCO- haya ido pasando de ser sumidero neto de carbono a constituirse en un emisor del mismo y de otros gases de efecto invernadero no puede ser un asunto banal en un contexto de cambio climático (Aguilera et al., 2015). Como tampoco hay que minusvalorar los procesos de contaminación química de suelos y acuíferos, la excesiva dependencia de insumos externos y energías fósiles en un marco de crisis energética o la pérdida de multifuncionalidad precisamente ahora que se preconiza una "nueva agroenergética".

En definitiva, no hay duda del carácter único y excepcional del olivar y, por tanto, de su condición de patrimonio de la humanidad. Pero el riesgo de no conocer la historia del cultivo implica no contar con su carácter cambiante, adaptativo y su importancia secular y puede suponer la sublimación del paisaje hoy dominante como evidencia única de su historia. El olivar actual, contiene saberes milenarios y ha estado presente en la vida cotidiana y en los grandes eventos de 
un territorio que, a su vez, ha albergado algunas de las civilizaciones más notables de la historia de la humanidad. En ese sentido, y por ello, el olivar es un indiscutible patrimonio de la humanidad que hay que reconocer, que cuidar y que salvaguardar, pero el modelo industrializado e impactante actual debe ser considerado solo como un renglón torcido de las últimas décadas en una historia milenaria, sin desconsiderar el riesgo de que puede quebrar su sostenibilidad futura.

Reivindicar nuestro olivar como patrimonio de la humanidad, debe significar no sólo un reconocimiento de sus saberes ancestrales, sino - sobre todo- un reaprendizaje de los mismos por parte de sus actuales cultivadores y productores. El reconocimiento comunitario de un valor como legado o herencia implica el compromiso con su sostenibilidad como tal valor y no meramente como precio de mercado. En unos momentos en que la crisis nos obliga a aguzar el ingenio y a recobrar sin nostalgias las ecologías de saberes y productividades como lógicas alternativas que hagan emerger lo escondido en tiempos de engañosa bonanza, la inclusión del olivar en la lista de Patrimonio de la Humanidad tiene que ser un acicate para que los olivareros recuperen los saberes y los tiempos perdidos $y$, con ellos, sus paisajes multifuncionales y variopintos como signos de desarrollo cualitativo y de respeto a la inteligencia mediterránea compartida y acumulada milenariamente.

Agradecimientos: Este artículo se enmarca en el Proyecto "Los paisajes culturales de la Lista de Patrimonio Mundial. Claves para su identificación y criterios para la gestión de dehesas, montados ibéricos y olivares mediterráneos" con REFERENCIA: CSO2015-65787-C6-6-P., financiado por el Ministerio de Economía y Competitividad, periodo 2016-2020.

Declaración responsable: Las/os autoras/es de este artículo, Juan Francisco Ojeda-Rivera, Carmen Andreu-Lara y Juan Infante-Amate, declaran que no existen conflictos de intereses en esta publicación compartida, con la que han pretendido desarrollar un método compartido de lectura transdisciplinar de paisajes, basada en el diálogo de un geógrafo, una pintora y un historiador, del que se espera haber obtenido un producto más valioso que el que hubiese salido de nuestras respectivas disciplinas e incluso del mero sumatorio de las mismas. Para llegar a las conclusiones transdisciplinares sintetizadas en la Figura 17 del artículo se ha ido produciendo una propuesta metodológica y una mirada físico-natural y geográfica al olivar en el mundo, por parte del geógrafo (Ojeda-Rivera); un recorrido sobre la evolución geohistórica y de manejos del olivar así como con el diseño de las figuras y tablas que se incluyen en esos apartados por el historiador (InfanteAmate), y unas creaciones pictóricas que condensen los valores que el imaginario colectivo ha ido atribuyendo al acebuchal-olivar a través del tiempo, ejecutadas por la pintora (Andreu-Lara). Tales aproximaciones interdisciplinares constituyeron las bases para desarrollar la buscada transdisciplinariedad, que se expresa en el último apartado hermenéutico y en las conclusiones. 


\section{Bibliografía}

Aguilera, E., Guzmán, G., \& Alonso, A. (2015). Greenhouse gas emissions from conventional and organic cropping systems in Spain. II. Fruit tree orchards. Agronomy for Sustainable Development, 35(2), 725-737. https://dx.doi.org/10.1007/s13593-014-0265-y

Beaufoy, G. (2001). EU policies for olive farming. Unsustainable on all counts. Brussels: BirdLife International. Retrieved from http://www.wwf.org.uk/filelibrary/pdf/oliveoil.pdf

Blondel, J. (2006). The 'design 'of Mediterranean landscapes: a millennial story of humans and ecological systems during the historic period. Human ecology, 34(5), 713729. https://dx.doi.org/10.1007/s 10745-006-9030-4

Delgado Bujalance, B. (2011). Reflexiones sobre el olivar (Unpublished).

Esponera, P. (1851). Del olivo y su cultivo (Memoria presentada a la Junta de Agricultura de la Provincia de Jaén). Madrid: Imprenta DFH del Castillo.

Florido Trujillo, G. (1996). Hábitat rural y gran explotación en la depresión del Guadalquivir. Sevilla: Dirección General de Arquitectura y Transportes.

Foraster, L. (2016). Transición agroecológica del olivar. Estudio de caso (Doctoral dissertation, Universidad Internacional de Andalucía, Sevilla, Spain).

Gómez Calero, J.A. (2009). Olivar sostenible. Prácticas para una producción sostenible de olivar en Andalucía. Retrieved from

www.ias.csic.es/sostenibilidad_olivar/BPA_2009/BPA VF_lan2010.pdf

González Bernaldez, F. (1992). La frutalización del paisaje mediterráneo. In Paisaje Mediterráneo (pp. 136-142). Milán: Electa.

Guzmán, J. R. (2005). Territorio y medio ambiente en el olivar andaluz. Sevilla: Consejería de Agricultura y Pesca.

Infante-Amate, J. (2014). ¿Quién levantó los olivos? Historia de la especialización olivarera en el sur de España (ss. XVIII-XX). Madrid: Ministerio de Agricultura, Alimentación y Medio Ambiente.

Infante-Amate, J., Villa, I., Aguilera, E., Torremocha, E., Guzmán, G., Cid, A., \& González de Molina, M. (2016). The Making of Olive Landscapes in the South of Spain. A History of Continuous Expansion and Intensification. In M. Agnoletti \& F. Emanueli (Eds.), Biocultural diversity in Europe (pp. 157-179). New York: Springer.

Junta de Andalucía, Consejería de Agricultura y Pesca (2002). El olivar andaluz. Sevilla. 
Lima Cueto, F. J., Gómezmoreno, M. L., \& Blanco, R. (2017). El olivar de montaña y la conservación del suelo en la transición de la economía orgánica a la industrial: el caso de Sierra de las Nieves (Málaga), 1940-1975. Ager, 23, 97-128.

Loumou, A.\& Giourga, C. (2003). Olive groves: The life and identity of the Mediterranean. Agriculture and Human Values, 20(1), 87-95. https://dx.doi.org/10.1023/A: 1022444005336 Molinero, F., et al. (Coords.) (2013). Atlas de los paisajes agrarios de España. Tomo I. Madrid: Ministerio de Agricultura, Pesca y Alimentación.

Muñoz-Cobo, J.M., Klemming, J. M., Romero, C., \& Torres, M. J. R. (2001). Análisis cualitativo y cuantitativo de las comunidades de aves en cuatro tipos de olivares en Jaén (I) comunidades primaverales. Boletín de sanidad vegetal. Plagas, 27(2), 259-274.

Muñoz Rojas, J. A. (2006). Textos poéticos (1929-2005). Madrid: Cátedra.

Naredo, J. M. (1981). La incidencia del «estraperlo» en la economía de las grandes fincas del Sur. Agricultura y Sociedad, 19, 81-129.

Ojeda, J. F. (2002). La viña, paisaje ético. Bollullos Par del Condado: Cooperativa vitivinícola.

Sánchez, J. (1924). Málaga. In Actas del VII Congreso Internacional e Oleicultura (pp. 650-655). Sevilla, December, 5-9. Madrid: Edición de Sucesores de Rivadeneyra.

Serra y Navarro, M. (1878). Elementos de agricultura. Jaén: Est. Hijos de D. José Francés.

Sieferle, R. P. (2001). The subterranean forests. Energy Systems and the Industrial Revolution. Cambridge: The White Horse Press.

Vanwalleghem, T., Infante-Amate, J., González de Molina, M., Soto, D., \& Gómez, J. A. (2011). Quantifying the effect of historical soil management on soil erosion rates in Mediterranean olive orchards. Agriculture, ecosystems \& environment, 142(3), 341351. https://dx.doi.org/10.1016/j.agee.2011.06.003

Zambrana, J. F. (1987). Crisis y modernización del olivar. Madrid: Ministerio de Agricultura, Pesca y Alimentación. 